\title{
Globalizacion, Medios de Comunicacion y Cultura en México a principios del siglo XXI
}

\author{
Dr. Javier Esteinou Madrid \\ Investigador Titular del Departamento de Educación y Comunicación de la Universidad \\ Autónoma Metropolitana, Unidad Xochimilco, México, D.F.
}

\section{RESUMEN}

El presente artículo plantea el estudio de los medios de comunicación en México, cuya operación ha quedado enormemente descuidada por el Estado y la sociedad civil. Es por ello, que ante el próximo gobierno es necesario repensar que hacer en términos políticos para crear otro proyecto colectivo de comunicación social que sí rescate los principios esenciales para democratizar a la sociedad mexicana.

\section{ABSTRACT}

The present article outlines the study of media in Mexico whose operation has been vastly careless for the State and the civil society. Because of this, it is necessary to think about a collective project of social communication to democratise Mexican society before the next government arrives to the power.

Palabras claves: Medios/México/Sociedad civil/Democracia.

Key Words: Media/Mexico/Civil Society/Democracy.

I.- Los medios de informacion colectivos como centro del poder contemporáneo. on la presencia de los medios de información y las nuevas capacidades
tecnológicas que han conquistado en México a lo largo del siglo XX,
como son su amplia cobertura informativa, su gran penetración mental,
su rápida capacidad de difusión, su enorme versatilidad semiótica, su gran perfeccionamiento técnico, etc; estos se han convertido en el centro del poder contemporáneo de nuestra nación. En este sentido, de haber sido instrumentos de difusión relevantes en 1920 en México y de convertirse en el cuarto poder político a partir de 1960 como corresponsales del poder, en la década de los años 90s. se transformaron en el vértice del poder actual. Es decir, ya no solo son instituciones importantes o el cuarto poder, sino que ahora son "el Primer Poder" que existe en nuestra sociedad. 
Así, las ágiles potencialidades avanzadas de las nuevas tecnologías de información para producir, difundir e internalizar datos y sentidos sobre nuestras conciencias, han modificado las reglas y dinámicas tradicionales con las que nuestra sociedad antaño se articulaba, organizaba y participaba colectivamente. Con ello, se ha producido un profundo cambio en la jerarquía de poderes que conforman el esqueleto del poder y de la movilización cotidiana de nuestra sociedad donde los medios de información ahora son el centro del poder.

Este creciente poder de los medios sobre la comunidad y los individuos ha creado, cada vez más, una sociedad mediática que ha producido una nueva atmósfera cultural colectiva de naturaleza "comunicósfera" que ha ocasionado que el conjunto de las principales instituciones de gobernabilidad ahora funcionen a distancia por intermediación de los canales de información, especialmente electrónicos y las nuevas tecnologías de información. La expansión de esta realidad mediática ha modificado la estructura y frontera del Estado mexicano y de la cultura nacional creando una nuevo tejido en la esfera del poder que ha dado origen al Estado Mexicano Ampliado. Así, observamos el surgimiento de la tele administración pública, el tele deporte, la telepolítica, la tele banca, la tele oración, la tele medicina, la tele venta, la telediversión, la telepolítica, la radio asistencia psíquico-emocional, la radio orientación vial, la radio iglesia, la radio orientación sexual, etc.

Con ello, el funcionamiento los medios ha atravesado la operación práctica de todas las instituciones sociales básicas para la dirección del país, al grado que ha substituido en algunos períodos o reubicado en otros a los órganos de administración social mas débiles o que están en crisis de funcionamiento y legitimación. Por ejemplo, ante la baja de credibilidad de la población en los partidos políticos, las órganos públicos y la iglesia, la capacidad persuasiva y seductora de los medios han construido nuevas credibilidades y hegemonías basadas en estrategias de mercado a partir del raiting.

Incluso, profundizando sobre la tarea histórica central que realizan los canales de difusión podemos decir que debido a su capacidad altamente educativa y persuasiva, al final del milenio los medios de difusión no sólo son el centro del poder político contemporáneo, sino que son, cada vez más, las instituciones de conformación del cerebro social de los habitantes del país. En este sentido, cada vez más, son elementos medulares del proceso de construcción social del cerebro humano, y por lo tanto, de conformación de la humanidad.

Así, a diferencia de los siglos anteriores, con la revolución informática las nuevas características con que los medios de información han transformado los procesos para producir, difundir e inculcar la información han convertido al siglo $\mathrm{XX}$ en un siglo corto, pues se han reducido los tiempos de conocimiento de la realidad y las distancias de interacción entre los hombres.

De esta forma, derivado de lo anterior se puede afirmar que en la actualidad, no existen vehículos más eficaces para transmitir la información colectiva a la 
sociedad que la radio y la televisión. Estos medios, de suyo neutrales como tecnologías, transportan los mensajes fundamentales que moldean la personalidad de los mexicanos. Así, las aspiraciones del pueblo, los anhelos del país que queremos ser y la visión del mundo y de la vida, se construyen en la nación lenta, cotidiana y eficazmente a través del contenido de la programación de los sistemas de comunicación colectivos.

Por lo tanto, ya no ha sido el discurso político ni la acción de los representantes populares y ni siquiera la prensa tradicional lo que ha permitido a los mexicanos tener una visión cotidiana de sí mismos y del futuro de nuestra nación. En la actualidad, son las redes televisoras y radiodifusoras, quienes acceden permanentemente a la mente de los mexicanos y les informan o les deseducan sobre la conducta a seguir en la sociedad contemporánea que nos corresponde vivir $^{(1)}$.

En este sentido, podemos decir que en el espacio de relación simbólica que permanentemente producen los aparatos cotidianos de comunicación entre emisores y colectividades, es donde diariamente se construye o destruye mental y afectivamente al Estado y a la sociedad mexicana. Por consiguiente, podemos afirmar que en la sociedad mexicana de la década del 2000, cada vez más, las batallas políticas o sociales se ganan o pierden en los medios de comunicación colectivos y no en otras áreas de las contiendas sociales.

De esta forma, la construcción o destrucción de la realidad masiva cotidiana, es decir, de lo que existe o no existe, de lo que es bueno o es malo, de lo que hay que recordar o hay que olvidar, de lo que es importante o no, de lo que es verdad o es mentira, de lo que son valores o antivalores, de lo que es la opinión pública o de lo que no es, de lo que es virtuoso o no, de lo que hay que hablar o hay que silenciar, de lo que hay que admirar o rechazar, de lo que es el éxito o el fracaso, etc, se elabora, cada vez más, especialmente en las grandes ciudades, desde los medios colectivos de difusión. Así, el peso de los canales de información masiva es tan acentuado sobre la conformación mental de la sociedad que podemos decir que la realidad no son los medios de información, pero los medios contribuyen sustancialmente a construir la realidad central que reconoce la mayoría de la población. No son la política, pero hoy día no se puede hacer política sin la acción persuasiva de los sistemas de información colectivos. No son el aparato jurídico, pero hoy día los medios se han convertido en los "tribunales electrónicos" que linchan o absuelven a las figuras públicas antes de que el Estado recurra a los procesos constitucionales de oficio. No son los partidos políticos pero producen el mayor caudillismo electrónico que toda la capacidad proselitista directa que realizan las organizaciones políticas. No son la economía, pero ninguna economía

(1) Labra, Armando; Prólogo, La legislación mexicana en radio y televisión, Colección Ensayos, Universidad Autónoma Metropolitana, Unidad Xochimilco, México, D.F., primera reimpresión 1989, página 7. 
contemporánea puede funcionar sin la cultura de consumo que producen de los medios de información, vía su práctica publicitaria. No son la memoria del país, pero hoy día la agenda del recuerdo social cotidiana se construye progresivamente desde los medios de difusión de masas, etc.

En una idea, a partir de las grandes capacidades persuasivas que han conquistado los medios sobre los campos de conciencia de los auditorios, las verdades e ideologías mediáticas substituyen, cada vez más, al resto de las verdades sociales, incluyendo a las jurídicas, éticas y morales.

Como demostración del alto grado de penetración de las industrias culturales en la vida cotidiana de los mexicanos, constatamos, por ejemplo, que en 1998 existen en la República Mexicana 595 estaciones de televisión divididas entre canales nacionales, repetidoras, televisoras locales, y televisoras de los gobiernos estatales. En cuanto a la radio existen 1.332 emisoras en el país, divididas en 875 estaciones en A.M. y 479 en F.M. En cuanto a los sistemas de satélites se cuenta con el complejo de satélites Morelos II, Solidaridad I y Solidaridad II que cubren todo el territorio mexicano y otras partes del continente americano (El sistema de satélites Morelos I ya terminó de operar con vida útil). En cuanto a los medios escritos México cuenta con 400 periódicos de circulación local y 192 revistas, la mayoría de circulación nacional y de periodicidad variable. En cuanto a las agencias de información existen 59 agencias de noticias, de las cuales 14 son nacionales y 45 internacionales, con 64 corresponsales extranjeros, 57 de periódicos y 7 de revistas ${ }^{(2)}$.

La proliferación de esta gran infraestructura informativa en el país ha contribuido a modificar sustancialmente los hábitos culturales de la vida cotidiana de los mexicanos. Así, observamos, por ejemplo, que al final del siglo XX los mexicanos son los habitantes que más ven televisión en todo el continente americano, con un promedio diario superior a las 4 horas $^{(3)}$. De aquí, que al final del milenio la población mexicana sea haya transformado de una cultura de lectores a una cultura de televidentes, de lo cual se deriva un peso muy sustantivo de los medios audiovisuales en la formación de sus gustos, actitudes, opiniones, conductas, mentalidades y visiones de la vida, en una idea, de la formación y operación de sus cerebralidades.

(2) Información Relevante Sobre Medios de Comunicación en México, Documento estadístico de apoyo preparado para la Conferencia Internacional sobre "El Derecho a la Información en el Marco de la Reforma del Estado en México", Cámara de Diputados, LVII Legislatura, mayo de 1998, México, D.F., 27 páginas.

(3) Un estudio reveló que los mexicanos son los que mas tiempo pasan frente a la televisión en América, Crónica, 7 de abril da 1998; Los mexicanos pasan mas horas frente a la televisión, El Nacional, 7 de abril de 1998. 
Esta asombrosa expansión tecnológico material de los medios de información ha creado a finales del siglo XX una sociedad mexicana altamente mediatizada en sus procesos colectivos de interacción masiva por las tecnologías de información. De aquí, la importancia central de efectuar una profunda Reforma del Estado en materia de comunicación y cultura colectiva que permita que el funcionamiento público de las industrias culturales se encuentre ética y responsablemente orientado y supervisado por el Estado y la sociedad civil mexicana.

\section{II.- Control y participacion en los medios de comunicación.}

No obstante que a principios del siglo XXI los medios de información gradualmente se han convertido en el centro del poder contemporáneo, su operación no ha funcionado en espacios neutros o independientes, sino que han operado vinculados a las necesidades de reproducción de nuestra sociedad en vías de industrialización y ahora de globalización. Dentro de este marco estructural, el margen de participación de los movimientos sociales a través de los medios de comunicación no ha sido monolítico; sino que ha oscilado formando una gama de intervención que varía desde los canales escritos, hasta los electrónicos. Así, encontramos que las vías a través de las cuales los movimientos sociales mexicanos han participado con mayor fuerza desde principios de siglo hasta la fecha para expresar sus intereses y demandas, se concentra con gran peso en los medios impresos y se cierra casi por completo en los canales electrónicos, particularmente, audiovisuales ${ }^{(4)}$.

De esta forma, la naturaleza social de los medios de comunicación desde un principio ha quedado determinada por la presencia de un fuerte contexto económico y político que ha condicionado herméticamente el uso social de los mismos por otros sectores más amplios que no sean los propietarios o representantes del

(4) Participación de los movimientos sociales, vía los medios de comunicación:

CUADRO No. 1.

DIAGRAMA DE PARTICIPACION DE LOS MOVIMIENTOS SOCIALES EN MEXICO A TRAVES DE LOS MEDIOS DE COMUNICACION.

MAYOR APERTURA A LA PARTICIPACION SOCIAL. MENOR APERTURA A LA PARTICIPACION SOCIAL.

$(+)$

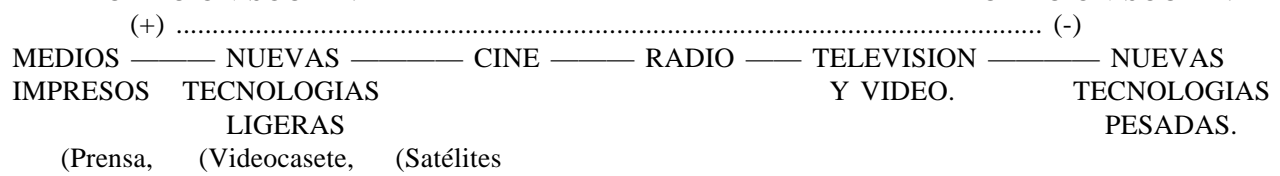
revistascomputadoras de

y personales, comunicaciones).

folletos). Compac disk,

etc.). 
gran capital interno y transnacional en el país. Esta situación ha alcanzado su mayor esplendor en el caso de la televisión mexicana, tanto pública como privada, pues es el medio que más ha llegado a ser monopolizado por el poder nacional al grado de que vía éste se ha construido otro proyecto cultural contrario al proyecto de los grandes grupos que sostienen nuestra nación.

En este sentido, derivado de este condicionamiento la televisión mexicana surge en la década de los años cincuenta adoptando el modelo comercial de desarrollo de la televisión norteamericana y enmarca mayoritariamente su funcionamiento bajo el régimen de concesión privada que conserva hasta nuestros días. Es dentro de este esquema mercantil que la televisión nacional se desarrolló y donde alcanzó hasta ahora su mayor dinámica de expansión e influencia sobre la cultura nacional.

Contraria y paralelamente a esta realidad privada, aparece de manera muy tardía, a finales de los años sesenta, la televisión pública en nuestro territorio. Su lenta incorporación al panorama cultural de la nación, provoca que ésta emerja y madure con una personalidad social poco definida, con menor experiencia audiovisual, reducido apoyo económico, bajo nivel de credibilidad en el auditorio, proyecto cultural confuso, mayores presiones burocráticas, menor cobertura geográfica de influencia, grandes contradicciones en sus líneas de dirección, etc.

Es por ello, que dentro de un clima de agotamiento de nuestro tradicional modelo de crecimiento hacia adentro y de incorporación intensiva de nuestra economía a los procesos de globalización mundial, nos preguntamos ¿Qué han hecho las empresas de televisión nacionales para permitir que los grupos sociales expongan colectivamente sus necesidades fundamentales y participen a través de éstos en los macro procesos de dirección del país?

En términos generales podemos decir que en comparación con las gestiones televisivas de los regímenes de gobierno anteriores, en esta nueva administración gubernamental la televisión ha conquistado algunos avances importantes, en el terreno administrativo, financiero, cultural, legal, tecnológico, reorganizativo, etc. sin embargo, no obstante los éxito alcanzados en diversos cambios, también podemos decir, que salvo algunas excepciones, la información televisiva que ha producido y difundido este proyecto cultural de gobierno, no ha permitido la expresión de las necesidades de los grandes grupos sociales a través de ésta; y en consecuencia, no se ha dedicado sustantivamente a crear conciencia sobre los principales problemas que debemos resolver para sobrevivir.

Así, observamos que no obstante que en la actualidad la sociedad mexicana ya ha llegado a alcanzar los 100 millones de habitantes, y pese a que, en última instancia, los grupos básicos que sostienen a nuestra nación son los que financian el funcionamiento de la televisión; confirmamos que la mayor parte de estos sectores básicos no tienen acceso para participar dentro de este medio de co- 
municación para exponer colectivamente sus necesidades e incorporarse a los procesos de gestión pública del país vía esta tecnología cultural.

En este sentido, constatamos, por ejemplo que las organizaciones campesinas no cuentan con espacios televisivos para desde estos solicitar apoyos crediticios para trabajar en el campo, exigir mejores precios de garantía a sus cosechas, demandar el reparto de tierras, denunciar el extendido cacicazgo y la corrupción de autoridades o funcionarios, etc. Los sindicatos tampoco cuentan con tiempo informativo para pedir aumentos salariales, elevar sus condiciones generales de vida, denunciar las anomalías existentes en el interior de las mismas, etc.

Los partidos políticos tampoco gozan de suficiente margen televisivo para fortalecer su participación en la sociedad, perfeccionar el sistema electoral, mantener contacto masivo con sus representados, difundir sus propuestas y posiciones partidistas, salvo en los períodos electorales, etc. Los numerosos grupos indígenas fundadores desde hace milenios de nuestro territorio y cultura, todavía, en el siglo XXI, no tienen ningún espacio en la televisión para expresar sus necesidades, dolor y tristeza generado desde hace 500 años con la Conquista Española, etc.

No obstante que actualmente vivimos una fase de colapso ambiental en el Valle de México y el resto del país por la profunda relación destructiva que mantenemos con la naturaleza, los movimientos ecologistas, no cuentan con ningún espacio de las redes nacionales de televisión para difundir su labor en pro de la defensa de la vida. Los sectores magisteriales, no obstante que sobre ellos descansa la formación del capital cerebral del país a través de su acción educativa, tampoco cuentan con espacios en los medios audiovisuales para contrarrestar la acción deformante de la cultura parasitaria que ha creado la sociedad de consumo y fortalecer con ello el proyecto educativo de la escuela nacional.

Otras células básicas como son los organismos no gubernamentales, las iglesias, los productores agropecuarios, los transportistas, los grupos de amas de casas, las asociaciones de padres de familia, los grupos de colonos, los estudiantes, los profesionistas, etc. tampoco disponen de espacios en las pantallas para plantear y discutir sus problemáticas particulares.

En este sentido, pensamos que debido a que no se ha permitido la participación de los grandes grupos en los medios electrónicos, particularmente en la televisión, tanto pública como privada, éstos continúan desvinculados del análisis sistemático de los grandes obstáculos que impiden nuestro desarrollo nacional y de la difusión constante de las posibles alternativas de solución para cada rama de nuestro crecimiento interno. Por ello, podemos decir que la televisión sigue funcionando como cerebro colectivo divorciado de las necesidades de nuestro cuerpo social, porque mientras vivimos cotidianamente una profunda crisis socioeconómica, que está por convertirse en severo conflicto político, la televisión nos orienta a pensar, prioritariamente, en el triple eje cultural del 
consumo, los deportes y las ideologías del espectáculo; y sólo ocasionalmente nos conduce a reflexionar y sentir los problemas centrales de nuestra sociedad. En una idea, la problemática nacional no pasa sustantivamente por la televisión lo cual, ha provocado la existencia de un modelo de funcionamiento esquizofrénico entre lo que difunde e inculca la programación televisiva y las necesidades o realidades que viven cotidianamente los grupos mayoritarios de la sociedad mexicana.

De esta forma, podemos afirmar que como en un acto de magia que se lleva a cabo ante los ojos de todos y el estupor de unos cuantos, desde hace tres décadas a la fecha, la televisión continúa realizando la hazaña verdaderamente fantástica de ocultarle su país a los mexicanos ${ }^{(5)}$. En síntesis, podemos decir que al funcionar como primer poder, los medios han construido por décadas un modelo dominante de comunicación que se ha caracterizado por dar voz y participación a una minoría; y silencio y marginación a la mayoría social.

III.- Tendencias informativas y culturales derivadas de la aplicación del tratado de libre comercio.

Le existencia de este modelo tradicional de comunicación nacional en la fase de la modernidad, se ha reforzado desde 1980 a la fecha con la gradual aplicación indiscriminada de los principios del mercado al terreno de la comunicación colectiva, especialmente, después de la firma del Tratado de Libre Comercio con Estados Unidos y Canadá (TLC), ocasionado, entre otras, las siguientes transformaciones sobre nuestra sociedad:

\section{1.- El Retiro del Estado Como Rector de la Cultura y la Comunicación} Nacionales. La mutación más grande que se ha producido ha sido el retiro creciente del Estado mexicano como instancia rectora de los procesos de cultura y comunicación nacionales, para delegar ahora su dirección a la dinámica del mercado bajo el mecanismo de acción de la oferta y la demanda informativa. Así, la rectoría del Estado en el campo de la conciencia de lo público ha quedado substituida por la intervención de las leyes del mercado con su "Mano Invisible" de regulación natural, que no ha sido otra realidad que la acción de la "Garra Invisible" de los intereses de los grandes monopolios de la difusión sobre el proceso de la cultura y la conciencia nacional.

De esta forma, ante el florecimiento en nuestro país en la década de los noventas de las tesis modernizadoras que han sostenido el adelgazamiento, la privatización, el repliegue, la desregulación, la globalización y la transnacionalización de todos los campos de lo público; hoy se ha formulado oficialmente, cada

(5) Expresión del Lic. Virgilio Caballero Pedraza. 
vez más, con mayor convencimiento que la dirección cultural de la sociedad mexicana no debe conducirse por la acción interventora de políticas planificadoras del Estado; sino que debe ser guiada por el equilibrio "natural y perfecto" que produce el juego de los "libres" principios del mercado entre productores y consumidores culturales.

\section{2.- EI Debilitamiento del Modelo de Medios de Comunicación de Servi-} cio Público. Presionado por el retiro del Estado como instancia rectora de la comunicación y por la imposición de las fuertes tendencias que han introducido las políticas econométricas neoliberales para convertir al Estado mexicano en una entidad "altamente eficiente", se ha generado una severa crisis y al mismo tiempo una desaparición creciente del modelo de medios de comunicación de servicio público que durante tres décadas habían funcionado en México; para ahora dar paso mayoritariamente al proyecto de mercado con sistemas de información privados altamente mercantilizados. Es decir, debido a que las leyes de la "libre competencia" han exigido que las empresas contiendan entre si con sus propios recursos y sin apoyo estatal, el gobierno mexicano ha retirado gradualmente los subsidios que fortalecían a los medios públicos y éstos cada vez más han tenido que luchar con sus propios recursos para sobrevivir ante la fuerte presión de las empresas privadas.

Ello significa, que el esquema de medios de comunicación de servicio público al dar marcha atrás el Estado Benefactor que lo mantenía a base del presupuesto oficial, crecientemente ha tenido que buscar a otras fuentes de ingreso para sobrevivir que, básicamente, han girado alrededor de la venta del tiempo de pantalla a las grandes empresas monopólicas y de la comercialización publicitaria. Esta situación ha obligado a que el modelo de información público se comercialice "reduciendo su pluralismo y originalidad, abriendo mayor campo aún a los grupos multinacionales tanto en lo que se refiere a la propiedad de las emisoras, como a su programación"(()).

De esta forma, derivado del orden social darwinista que ha impuesto el neoliberalismo con la práctica del TLC para que la sociedad funcione libremente beneficiando al más fuerte, se ha comprobado la inclinación progresiva del Estado mexicano para reducir o abandonar el financiamiento del modelo de medios de comunicación de servicio público a través de permitir la veloz privatización y la adopción del nuevo esquema comercial que dirigen los principios del mercado. En este sentido, al final de la década de los noventa nos enfrentamos, a corto plazo,

(6) Giordano, Eduardo y Zeller, Carlos; Europa en el Juego de la Comunicación, Colección Impacto, Los Libros de Fundesco, Fundación Para el Desarrollo Social de las Comunicaciones (FUNDESCO), Madrid, España, 1988, p-250. 
a una transformación del modelo de comunicación pública, y a largo plazo, quizás a su desaparición o existencia muy restringida.

Con ello, se ha observado el tránsito radical de un proyecto de comunicación y cultura colectivas dirigidas por el Estado, por más deficiencias, limitaciones y errores que haya tenido; a una práctica informativa fenicia conducida por el mercado orientada por el objetivo de producir ganancias rápidas, a costa de lo que sea.

3.- La Supremacía del Modelo de Comunicación Comercial-Privado. Con el retiro del modelo de medios de servicio público que ha exigido el esquema de desarrollo del Tratado de Libre Comercio, el sistema de medios comercial-privados se ha expandido notablemente en el país, llegando a ser éste el patrón dominante en nuestra atmósfera cultural, y con ello, se ha privatizado el campo de lo público. Es decir, al final del siglo XX las políticas culturales públicas y colectivas que se elaboran en nuestra sociedad, cada vez más, se construyen desde las necesidades privadas de la reproducción del capital y no desde las necesidades de avance y humanización de la población.

De esta manera, al concluir el milenio el Estado y la sociedad mexicana cuentan con menor infraestructura mental y comunicacional para crear la cultura indispensable que demanda el proceso de sobrevivencia social de nuestro país y con mayor logística cultural para crear las condiciones subjetivas de reproducción del capital ampliado a escala global.

4.- La Aplicación de la Política del "Laissez Faire Informativo". Para que el modelo de desarrollo modernizador se consolide en México con el TLC, ha sido indispensable la creación de una nueva conciencia masiva modernizadora que respalde y afiance las acciones de operación del mercado. Dicha conciencia ha producido, a nivel masivo, a través de los medios electrónicos de comunicación, las condiciones subjetivas necesarias para el funcionamiento de nuestra sociedad dentro de las nuevas relaciones competitivas del mercado mundial.

La esencia de ésta conciencia modernizadora ha formulado que ante la nueva globalidad internacional para ser eficientes, especialmente, en el terreno comunicacional; hay que aceptar indiscriminadamente la propuesta de asimilar los principios del "laissez faire informativo" en el terreno comunicativo o cultural, o lo que es lo mismo, asumir la mentalidad de que "lo que no deja dinero a nivel cultural, no sirve”. Bases que, llevadas a sus últimas consecuencias, en la práctica real han planteado el peligro de que en vez de fortalecer nuestra cultura nacional en este período de globalización, esta se flexibilice, y en ocasiones, hasta erosione más sus valores para incorporarnos eficientemente como sociedad y sin restricción alguna a la nueva estructura de competencia y de acumulación de los mercados mundiales. 


\section{5.- La Desrregulación y Autorregulación Creciente de las Comunicacio-}

nes. Al convertirse los procesos de comunicación en elementos estratégicos para la realización y reproducción del sistema económico, con la aplicación del TLC el gobierno y los concesionarios de los medios de información han planteado insistentemente que "en un mundo sistémico, sin fronteras, competitivo y globalizado, para que la dinámica del mercado se pueda realizar se requiere libertad de información. Por ello, no deben ponerse más regulaciones que las necesarias a la libertad de expresión en México, so pena de caer en burocratismos extremos o lo que es peor, en la inoperancia de la ley. La sobre reglamentación se opone al avance económico"(7).

En consecuencia, lo que se debe fomentar en las sociedades modernas crecientemente competitivas es el libre flujo de la información y no su restricción. Por lo tanto, el funcionamiento de los procesos de comunicación no deben reglamentarse con normatividades rígidas, sino sólo se deben crear mecanismos muy flexibles que permitan la autorregulación de los medios de difusión, como son los Códigos de Etica, los Tribunales de Honor y los Reglamentos de Buen Comportamiento Profesional, etc.

Con la propuesta de la desregulación del funcionamiento de los medios de información en México y su substitución por los procesos de "autorregulación absoluta" por parte del gobierno y de los propietarios, se ha caído en la concepción liberal extrema de crear el "Estado Cero" en el terreno comunicativo. Esta concepción plantea que el Estado no es necesario como instancia rectora para dirigir a la sociedad, ya que ésta es tan perfecta que se puede autoconducir a sí misma por las leyes de la mano invisible de las lógicas del mercado. Así, se ha formulado que en materia informativa el Estado debe reducirse a su mínima expresión (fórmula cero), para dejar que la sociedad se conduzca por otros mecanismos de autorregulación del poder.

Dicha teoría y práctica económico-social ha demostrado, a lo largo del siglo XX su enorme fracaso y límites al reflejar que, finalmente, toda sociedad moderna siempre requiere la presencia de un sólido Estado rector que equilibre los desajustes y las crisis que produce el funcionamiento autónomo o desbocado de la dinámica del mercado. Es decir, para crear las mínimas condiciones de gobernabilidad en el México contemporáneo, es necesario que todas las acciones públicas colectivas estén reglamentadas por la ley, pues de lo contrario se crean las bases oficiales para el surgimiento de los grandes espacios de anarquía social.

(7) Palabras de Sr. Emilio Nassar, Presidente de la Cámara Nacional de la Industria de la Radio y la Televisión (CIRT), en la Clausura del Simpósium sobre Libertad de Expresión y Responsabilidad Social, Cámara Nacional de la Industria de la Radio y la Televisión (CIRT), World Trade Center, México, D.F., 21 de julio de 1998. 
Es por ello, que la autorregulación de los medios de comunicación vía los Códigos de Etica y otros recursos morales, son mecanismos colegiados muy útiles que pueden ayudar a garantizar complementariamente el funcionamiento de los medios de comunicación, pero nunca deben operar como elementos únicos o solos para normar y conducir socialmente esta estratégica acción colectiva. Una tarea tan central para construir una sociedad democrática, equilibrada y participativa no puede quedar expuesta a los altibajos subjetivos, caprichosos o discrecionales de los intereses políticos del poder o sujeta a la dinámica de la "Mano Invisible del Mercado"; sino que debe ser reglamentada con toda exactitud por el interés colectivo, como cualquier otro derecho social básico, para garantizar su existencia y sana aplicación comunitaria.

De lo contrario, siguiendo el razonamiento de la lógica autónoma del mercado por sobre el orden social regulado colectivamente, también podemos demandar que no existan reglamentos de los cuerpos de policía, pues las comunidades pueden autoregular espontáneamente sus delitos. No se requieren leyes para normar el servicio de recolección de basura, porque la sociedad por sí misma puede autoregular cómo tirar sus desperdicios orgánicos. No se requiere una legislación de comportamiento bancario, pues los banqueros se pueden autoregular a sí mismos en beneficio de la sociedad. No es indispensable una legislación sobre la educación básica, pues cada ciudadano puede asegurar por sí mismo su formación educativa. No es necesario un reglamento fiscal, pues todos los ciudadanos pueden autoregular voluntariamente el pago de sus impuestos, etc. En suma, el Estado sale sobrando como órgano de regulación colectiva, pues la sociedad se puede autoregular a sí misma en todos los órdenes de la vida ${ }^{(8)}$.

Debemos de considerar que la ética no puede sustituir o suprimir al derecho, sino sólo enriquecerlo y complementarlo. No podemos cambiar el estado de derecho por la aplicación de un "eticómetro" de los concesionarios y empresarios de los medios de comunicación que es un instrumento subjetivo de buena voluntad, absolutamente vulnerable ante las fases de presión económica y política reales, como lo ha demostrado la historia de la comunicación nacional a lo largo del siglo $\mathrm{XX}^{(9)}$.

(8) Para ampliar este punto consultar Javier Esteinou Madrid, El Derecho a la Información y la Democratización del Estado Mexicano, Revista Iberoamericana de Derecho a la Información №. 2, Año 1, Programa Iberoamericano de Derecho a la Información de la Universidad Iberoamericana y Fundación Manuel Buendía, Departamento de Comunicación, Universidad Iberoamericana, Plantel Santa Fe, México, D.F., septiembre - diciembre de 1998, páginas 59 a 81.

(9) Ikram Antaki, conceptos expresados por la escritora en la conferencia de prensa, foro sobre Libertad de Expresión y Responsabilidad Social, Cámara Nacional de la Industria de la Radio y la Televisión (CIRT), World Trade Center, México, D.F., 21 de julio de 1998. 


\section{6.- El Diseño de la Comunicación Social Desde la Dinámica de la} Reproducción del Capital. Con el lugar estratégico que el nuevo modelo de desarrollo modernizador le ha concedido al mercado para ser el eje fundamental que dirija y modele a los procesos sociales, éste se ha convertido en el condicionante central del cual se deriva el origen, el sentido y el destino de la producción cultural y comunicativa en nuestro país. Es decir, en la década de los 90s. la verdadera reactivación del proyecto de comunicación y de la cultura nacional, no ha surgido de la antiquísima demanda de los grupos sociales básicos por resolver las necesidades de comunicación social más apremiantes de la población; sino que se ha derivado de la incorporación acelerada de nuestra sociedad al mercado mundial, que no es otra realidad que la reactivación y la ampliación intensiva del proyecto económico super transnacional en la periferia.

La sociedad civil o los grupos emergentes sólo aparecen en la programación de los medios de difusión colectivos cuando desde los criterios del negocio son "noticia" o un "objeto informativo" atractivo que puede elevar el RAITING de las empresas, pero no son considerados permanentemente como sujetos o entidades generadores de opinión que tengan derecho a un espacio colectivo permanente de participación informativa. Es la lógica de oportunidad económica del raiting la que decide cuando participa y la sociedad civil dentro de los medios y cuando no.

\section{7.- El Mercado Como Marco Axiológico de Valoración de la Vida.} Desde una perspectiva humana, el ejercicio de la práctica comercial sobre la base cultural ha significado que, cada vez más, el mercado ha sido la autoridad que determina el valor de las personas y la vida y no las fuerzas y procesos sociales en los que éstos están inscritos. Esto es, el reconocimiento social, la dignidad de la persona, su retribución económica, etc., es crecientemente definido y valorado por el mercado y no por las dinámicas de justicia y humanización.

Por ejemplo, esta situación se comprueba en el campo laboral de nuestra sociedad, cuando, paradójicamente, constatamos que contrariamente a los precedentes que caracterizaban a nuestras culturas madres donde el "Hombre Viejo" era más valorado como sabio para participar y dirigir al conjunto social; ahora con la introducción creciente de la lógica del mercado en las relaciones contractuales presenciamos que en el momento en que el ser humano se acerca a los 40 o 45 años de edad y está en su fase más madura y experimentada de la vida, ya no es contratado por la mayoría de las empresas por no ser competitivo. Esto comprueba que cada vez más el valor de lo humano está determinado por el mercado y no por los procesos sociales.

8.- La Cultura Determinada Por el Mercado. En términos educativos, la aplicación del modelo de mercado al terreno cultural ha representado que, en la actualidad, cada vez más, sean las bases de la mercadotecnia las que gobiernan la 
orientación y la acción de las instituciones culturales y comunicativas de nuestra Nación; y no las directrices del desarrollo social y espiritual de nuestra comunidad. Es decir, la modernización neoliberal básicamente ha reducido el proyecto comunicativo y cultural del Estado y de la sociedad a fortalecer y expandir las relaciones de mercado en nuestra República; y no a ampliar y reforzar los procesos culturales más abiertos, democráticos y participativos que durante tanto tiempo han demandado los grandes sectores básicos de nuestro territorio.

9.- La Cancelación de la Cultura Humanista. Desde el punto de vista de la formación de conocimientos la aplicación de Ley del Mercado al campo educativo está cancelando en México las carreras de Filosofía, Antropología, Sociología, Ciencia Política, Historia y otras disciplinas humanistas por asegurar que no son rentables o necesarias para los criterios de la modernidad por no ser productivas. Ante esta realidad debemos preguntarnos i Qué sucederá con una sociedad que progresivamente cancela la existencia de las disciplinas especializadas en su autoconocimiento como sociedad ?. Frente a esta realidad se puede decir que al aplicarse esta política tan pragmática se están formando las bases de una "ceguera social" de grandes dimensiones, pues los principios del mercado están abortando las áreas del conocimiento humano especializadas en el análisis propio de la comunidad. Ante ello, debemos interrogarnos i A dónde va una sociedad que ve todo, excepto a sí misma?.

10.- El Acrecentamiento de los Conflictos Culturales. Con la introducción extensiva de las leyes del mercado al terreno cultural y comunicativo, oficialmente se planteó hace varios años que dichas actividades se volverían más productivas, que se romperían los monopolios tradicionales en éste rubro al promoverse la libre competencia cultural, que se aumentarían la calidad de los productos elaborados, que se abrirían nuevos espacios de participación social dentro de ellos, que se elevaría la eficacia de las dinámicas culturales, que se agilizaría la producción comunicativa, que se aceleraría la modernización informativa, que se ampliaría y versatilizaría las fuentes de financiamiento de las empresas culturales, que se aceleraría la apertura de nuestra estructura mental al flujo mundial de información, etc; en una idea, que se enriquecerían fundamentalmente estas actividades al vincularse con los procesos de la modernidad.

Sin embargo, no obstante estas posibles ventajas que ha prometido alcanzar la aplicación acelerada de los principios de las leyes del mercado sobre otras lógicas sociales en el terreno comunicativo-cultural con el establecimiento trilateral del Tratado de Libre Comercio; observamos que dichas acciones no han sido fuerzas o dinámicas suficientes para resolver las tremendas contradicciones culturales e informativas que existen en nuestra sociedad. Es más, se ha constatado que debido a la naturaleza eminentemente mercantil de esta racionalidad económica 
aplicada al campo cultural, en lugar de resolver nuestros problemas de comunicación, en el fondo han acrecentado nuestros conflictos de cultura nacional. Esto debido, a que en diversos momentos este fenómeno ha llegado a ser la aplicación de una falsa ley entre libre oferta y demanda entre fabricantes y compradores, por las siguientes dos razones:

En primer lugar, porque hoy día esta realidad se encuentra profundamente alterada por la deformación del consumo que actualmente realiza la actividad publicitaria de los grandes monopolios económicos. Es decir, en la sociedad mexicana de finales de milenio, en muchos casos, ya no existe una demanda natural del consumidor; sino crecientemente asistimos a una decisión o gusto inducido por la enorme saturación publicitaria que cotidianamente producen los medios de comunicación de masas, especialmente electrónicos, sobre los diversos campos de conciencia de la población. Esta situación ha avanzado a tal extremo que en la actualidad ha ocasionado que muchas veces la demanda dependa de la oferta y no la oferta de la demanda: Las mercancías que se ofrecen, se venden, no tanto por las rigurosas características físico-materiales que poseen; sino por el estratégico papel que ejercen las técnicas de persuasión publicitaria sobre nuestros sentidos e inconsciente ${ }^{(10)}$.

Por consiguiente, en la actualidad, en muchos casos, el mercado ha pasado de ser una relación de "equilibrio natural" entre los elementos económicos de la producción y el consumo; para convertirse en la imposición de una relación artificial de los grandes monopolios sobre la población, para satisfacer sus necesidades de concentración material.

En segundo lugar, porque aunque en la exposición teórica de las tesis clásicas de la libre competencia se formula que ésta se da con toda libertad; en la práctica real del liberalismo más avanzado que hoy experimentamos se confirma que ésta no existe con tal apertura; pues, cada vez más, se da un proteccionismo acentuado de las naciones más desarrolladas en favor de sus áreas económicas mas frágiles. Esto significa, que a través de la aplicación de los principios del mercado a lo que nos enfrentamos en el fondo no es a una dinámica de libre competencia; sino al autoritarismo económico de los grandes trusts que actúan en nuestro país.

Esta práctica ha contribuido a aumentar los problemas culturales y a debilitar la estructura y contenidos de nuestra cultura nacional.

11.- El Reforzamiento del Modelo de Comunicación-Mercado. Al ser progresivamente regida la cultura y la información por las leyes del mercado el

(10) Promotor y no regulador el papel del Gobierno, Excelsior, 30 de septiembre de 1991; ¿ Ensayo de la Economía de mercado?, Excelsior 16 de diciembre de 1991; ¿ Resolver los problemas con la Ley de la Oferta y la Demanda?, Excelsior, 4 de enero de 1992. 
proyecto de conciencia y comunicación colectiva que se ha producido en nuestro país, a través de los medios de difusión masivos y de otras infraestructuras culturales, ha sido una propuesta lucrativa de acumulación, que se ha regido, entre otros, por los siguientes 16 principios $^{(11)}$ :

A.- La Comunicación Como Aceleradora del Capital. A partir de la aplicación de las reglas del Tratado de Libre Comercio, los procesos de comunicación se han concebido crecientemente como instrumentos aceleradores del proceso de realización de capital y no como herramientas para la elevación de la conciencia y el cambio colectivo para resolver nuestros problemas de crecimiento nacional. Esto, ha contribuido a producir una nueva valoración estratégica del campo de las telecomunicaciones y de la industria audiovisual que ha desatado una lucha nacional y continental por la concentración privatizada de las cadenas de difusión sin ningún precedente histórico en el país y la región.

B.- La Comunicación Como Mercancía. Para adecuar el espacio cultural de la sociedad mexicana a las nuevas necesidades del mercado que plantea el TLC, se ha alterado la concepción tradicional de la naturaleza de la actividad comunicativa que la comprendía como un producto social y se ha pasado, con mayor velocidad, a entenderla ahora como una simple mercancía mas que debe estar regida por los principios de la oferta y la demanda.

C.- La Obtención de la Ganancia a Corto Plazo. Cada vez más, se ha buscado obtener la ganancia a corto plazo a costa de lo que sea. Mientras menor sea el tiempo de recuperación de la inversión realizada, mayor atractivo es el proyecto. Esto representa, que las inversiones mayoritarias que se destinan al terreno cultural y comunicativo están definidas muy directamente por la rapidez de la recuperación de la ganancia económica y no por otros criterios más humanos y equilibrados que anteriormente introdujo el Estado Benefactor.

D.- Recuperación de la Ganancia en Términos Monetarios. La ganancia ha sido solicitada en términos monetarios y no de otro tipo de retribución, como puede ser el "enriquecimiento social" o la "humanización de la población" o el "cambio de conciencia colectiva". Para la realidad cultural e informativa de mercado esto significa que aquellas actividades que no producen

(11) Para ampliar más este punto consultar Javier Esteinou Madrid, La Comunicación y la Cultura Nacionales en los Tiempos del Libre Comercio, Editorial Fundación Manuel Buendía, México, D.F., 1993, páginas 119 a 203. 
"ganancias pecuniarias" y no de otro tipo, no son apoyados por las principales instituciones comunicativas del país. Por consiguiente, los proyectos culturales de apoyo al desarrollo social han quedado crecientemente marginados o han desaparecido.

E.- El Uso de Ideologías Para Abrir las Fronteras Culturales. Con el fin de ampliar más los márgenes de la acción transnacional sobre el campo de la cultura y la comunicación en el proceso de modernización que vive nuestro país con el Tratado de Libre Comercio, el mercado mundial ha recurrido crecientemente al uso de dos ideologías neoliberales para legitimar su avance y penetración en la periferia: la tesis del "Libre Flujo Internacional de la Información" y la ideología del "Acceso a la Modernidad Cultural".

Así, por una parte, argumentando que en la "Era de la Información" el mundo se ha convertido en una "aldea universal" a través de la expansión de las telecomunicaciones y el crecimiento de las redes de información, que ha ocasionado que todas las culturas estén interrelacionadas entre sí, derrumbando las "Fronteras Culturales"; se ha revitalizado la tesis del "Libre Flujo Internacional de la Información" para ampliar las posiciones del capital. Justificación, que en el fondo, no es otra cuestión que la premisa para permitir la fácil difusión y penetración de las imágenes transnacionales a todas las zonas del planeta, pues son sólo estas empresas las que pueden competir intensamente a escala global.

Por otra parte, paralelamente se ha promovido la adopción de la ideología del "acceso a la modernidad cultural" que en términos de concepciones de masas ha sido la visión que intenta homogeneizar la mayor parte de los campos de imaginarios sociales en base a los nuevos valores del consumo y el disfrute neoliberal para facilitar la expansión del mercado capitalista que exige el nuevo proceso de concentración de capital a escala mundial. Así ha surgido en el México moderno de la década de los 90s. un nuevo autoritarismo simbólico que se basa en la cancelación de las riquezas y diferencias de las diversas manifestaciones culturales de los grupos sociales, para dar paso a la formación de una nueva hegemonía ideológica de los monopolios locales y transnacionales en el campo de la cultura nacional. Con ello, se ha impuesto un concepto de calidad, de estética y de modernidad cultural que parte de lo exótico, lo folklórico, lo menudo, lo anecdótico, lo atomizado, lo frívolo, y lo tecnológico; marginando las peculiaridades de lo propio y lo trascendente en nuestro país.

Con esto, las instituciones representantes del comercio internacional han exigido mediante sus acciones diplomáticas, políticas, económicas, y especialmente de mercado, que nuestros valores e identidades nacionales se flexibilicen y abran a la modernidad para "formar un mercado universal sin barreras o 
límites"(12), a través de sus campañas de marketing hasta lograr que estas se adapten de manera más favorable a su nueva dinámica de concentración material.

F.- La Presencia del Malthusianismo Cultural. Con el reinado de los principios del mercado en el campo cultural, cada vez más, hemos presenciado la práctica de un "malthusianismo cultural" que ha permitido que sólo sobrevivan aquellas estructuras de conciencia que sean las más aptas para existir, desde los criterios del mercado. Así, con la aplicación de la "Mano Invisible del Mercado" sobre los procesos de comunicación la conciencia de lo social, ha sido desplazada para dar paso a la mentalidad de los negocios, el pensamiento de la ganancia ilimitada, el deseo del lucro, la inclinación dominante por el pragmatismo económico, la ideología de la posesión material como sentido de la vida, y la visión del progreso técnico como nueva religión, por encima de otros valores urgentes para la sobrevivencia colectiva.

En éste sentido, mientras en nuestra sociedad ha existido la necesidad estratégica de contribuir a producir desde los medios de comunicación, especialmente electrónicos, una mentalidad para la sobrevivencia social como es la construcción de una cultura ecológica, una cultura del agua, una cultura de la civilidad urbana, una cultura de la racionalización de los recursos no renovables, una cultura de la tolerancia humana, una cultura de la defensa de las especies animales, una cultura de la protección de la biodiversidad, una cultura de promoción de la vida, etc.; en ese mismo contexto de prioridades sociales, los canales de difusión electrónicos gobernados por los principios del mercado han tendido a construir una atmósfera de desperdicio cultural al producir una cultura de la frivolidad, una cultura del hiperconsumo, una cultura de la "novedad", una cultura de la transnacionalización, una cultura light, una cultura del espectáculo, una cultura del "star system", una cultura del Show, etc., que son altamente rentables, a corto plazo, pero que nos han llevado a despilfarrar la enorme energía humana que existe en el país para enfrentar nuestros grandes problemas de crecimiento y de sobrevivencia humana.

Hay que recordar que el mercado por sí mismo no tiene ética, ni corazón, ni se preocupa por lo humano y lo social. Su objetivo es la rápida y creciente acumulación de riqueza a expensas de lo que sea. Por consiguiente, es una ley que en la medida en que funciona autónomamente, sin sólidos contrapesos planificadores puede introducir en las comunidades una relación social de comunicación salvaje.

(12) Concepción del ex presidente norteamericano Ronald Reagan. 
G.- La Transformación de los Valores. Así como el capitalismo Mexicano para afianzarse en su fase de industrialización creó a mediados del siglo XX un tejido cultural consumista que con el tiempo se convirtió en la religión de las ciudades, desde la cual los individuos construimos gran parte de nuestro sentido más profundo para vivir y apoyamos el modelo de acumulación material; ahora, al final del siglo XX el "capitalismo modernizador" para consolidarse en su etapa neoliberal de apertura de fronteras ha requerido producir otros rasgos de la identidad nacional a través de una nueva estructura de valores algunos de cuyos puntales han sido la eficiencia maquinizada, la tecnificación, el pragmatismo, la supercompetencia, la privatización, la obsolescencia, la desregulación, la desestatalización, la internacionalización, la globalización, la aceleración, etc.

Nueva estructura axiológica que se ha distinguido por cancelar los valores del antiguo "Estado del Bienestar" nacional generado a partir de la Revolución de 1910, e introducir los valores del moderno "Estado Neoliberal" que mantiene como centro de gravedad el "laissez faire, laissez passer" del proyecto de acumulación ampliada en el campo de la comunicación, la cultura, la conciencia y el espíritu. De esta forma, podemos afirmar que con el proceso de globalización se ha intensificado la proliferación de diversos órdenes y espectativas pragmáticas del conocimiento y de la vida. En particular, "se da un mayor énfasis científico y tecnológico en nuestra tradición intelectual; que hasta el momento ha sido más propicia a la influencia de la cultura humanista y jurídica"(13).

Así, proyectando sobre el campo de la conciencia colectiva las nuevas determinantes estructurales que gradualmente ha impuesto el programa de crecimiento neoliberal, catalizado por el Tratado Trilateral de Libre Comercio, observamos que la moderna subjetividad que ha producido la estructura cultural y los medios electrónicos está caracterizada, en parte, por fomentar el individualismo por sobre las relaciones solidarias. Acentuar la competitividad por sobre el trabajo compartido ("Tequio"). El canibalismo salvaje por sobre la fraternidad. La marcada admiración por lo extranjero que por lo nacional. El interés por la no planificación colectiva sino por la altamente privatizada. La lucha por la libertad y felicidad aislada y no por la grupal. El valor supremo de la "eficiencia" por sobre otras metas humanas superiores. El abandono de los valores tradicionales para asimilar los "modernos lights". El dinero como base del reconocimiento y la valoración social. El hedonismo y la "Cultura Narcisista del Yo", como nuevo cristal para mirar la vida. La tecnificación extrema como sentido del éxito y no el diálogo y el acercamiento humano. Exaltar el alto pragmatismo por encima de otras cualidades humanas superiores. Promover el "futuro funny" que el de la participación creciente en nuestro proceso histórico. El impulsar el "culto a la 
juventud" por ser la etapa más productiva del individuo y el desprecio a los viejos por improductivos. La predilección por la modernidad entendida como el estilo de vida que permanentemente se ajusta a la adquisición de la última novedad y el rechazo a lo tradicional y lo antiguo. La invasión compulsiva de la vida privada por las industrias culturales y no el incremento de la "vida interior". La invención de una nueva identidad basada en la mayor asimilación de las culturas externas y no en el enriquecimiento del "México Profundo". El aprendizaje del idioma inglés para expandir el código lingüístico de la ampliación del capital, por sobre la asimilación del castellano y otras lenguas indígenas propias. La realización del principio de ganancia salvaje a costa de lo que sea y no la obtención racional de la riqueza respetando los ordenes naturales de la vida. La acelerada norteamericanización de nuestra cosmovisión y no el regreso a las formas milenarias de sabiduría de nuestras "culturas negadas". La construcción de la "alegría" a partir de la adquisición de lo ajeno y no del dominio creciente de lo propio, etc. .

De esta manera, a partir de la aplicación del proyecto neoliberal en la sociedad mexicana nos enfrentamos a la redefinición y cambio profundo de nuestra identidad psíquica, cultural y humana como sociedad pluriétnica y pluricultural; para ahora incorporar otros marcos de cosmovisión y de prácticas de la existencia desde las premisas de la "modernidad". Bases de visión de la vida y del espíritu que mayoritariamente tienden a ser la mirada de la reproducción ampliada del capital a escala planetaria.

En este sentido, podemos decir que en las entrañas de nuestra vida cotidiana hoy estamos ante el silencioso embate de nuestras culturas y diferencias ideológicas tradicionales para reacomodarlas o destruirlas dentro del nuevo esquema de división del mundo por modernos bloques hegemónicos. Recomposición mental que gradual y silenciosamente está unificando los campos imaginarios, las aspiraciones profundas y las cosmovisiones de los seres a través de la construcción de un nuevo concepto de relaciones humanas, de placer, de triunfo, de trabajo, de felicidad, de moral, de religión, de etnia, etc., en una idea, de un nuevo sentido y estilo de vida determinado por las nuevas exigencias de maduración del comercio mundial. Situación que se condensa en la creación del nuevo "México Imaginario de la Fase de la Globalización Mundial", que se opone al México profundo y real de finales del siglo XX.

Ante este panorama, es conveniente considerar que si la historia de la publicidad en México a lo largo de los últimos 40 años ha demostrado que con tal de vender las mercancías para acelerar el proceso de circulación del capital, ésta estuvo dispuesta a banalizar e incluso prostituir finamente la imagen de la mujer para presentarla fundamentalmente como un objeto de uso sexual, a añadirle cualidades falsas o "fetichizar" los productos para hacerlos más atractivos, a crear necesidades artificiales en los consumidores para alentar la compra, a hacer creer que el valor de 
las personas se deriva de la marca que eligen y no en el porcentaje en que se conocen a sí mismos, a impulsar que el éxito de los individuos se da en la medida en que se acumulan pertenencias y no en el grado en que se es humano, a modificar la identidad nacional para revalorarse socialmente a través de la adquisición progresiva de más productos transnacionales, etc.; ahora, es posible pensar que al entrar intensivamente en la fase de desarrollo de "libres fronteras" se construirá masivamente a través de las industrias culturales una visión del hombre y de la vida cada vez más condicionada por los requerimientos de expansión y fortalecimiento del mercado universal y no de la humanización de los individuos. De aquí, la importancia estratégica en plena globalización de rescatar y reforzar nuestra base de identidad cultural para incorporarnos de manera firme a los nuevos cambios inevitables que plantea el drástico reordenamiento económico, político y cultural del mundo.

H.- La Anarquía Cultural. La aplicación de la dinámica de la "Mano Invisible" del mercado sobre los procesos de comunicación y cultura ha generado en la sociedad mexicana un fuerte desorden informativo que ha producido una anarquía cultural al permitir que estemos altamente informados sobre lo secundario y no sobre lo fundamental para sobrevivir.

I.- Surgimiento del Neoconsumo Nacional. Motivado por la necesidad de movilizar el enorme flujo de mercancías que acceden al país por la apertura de fronteras comerciales a través del Tratado de Libre Comercio, se ha producido en nuestra República una nueva mentalidad neoconsumista que actúa como cemento ideológico que articula a las todas las clases sociales en una sola práctica: el neoconsumo. Dicha ideología se ha caracterizado por difundir intensamente la propuesta que plantea que para ser modernos, estar al día y mantenerse adaptados a la permanente dinámica de cambio que se vive en el mundo, hay que consumir constantemente los nuevos productos, especialmente extranjeros, que produce la modernidad. De esta manera la nueva ecuación social formula la concepción: consumo, igual a progreso social.

Con ello, las leyes internacionales del nuevo patrón de acumulación de capital que se han gestado y que permean todos los niveles de nuestra sociedad, han exigido en la esfera cultural que el alma colectiva que se construya en el país a través de los canales electrónicos de información se base en una visión de la vida más cosificada y transnacionalizada que nos lleve a saber cada vez más del gran mundo externo y cada día menos de nosotros como República y como personas. En una idea, a lo largo de este período de libre comercio se ha buscado producir culturalmente en México a los "hombres universales" y a los "ciudadanos del mundo", capaces de consumir cualquier mercancía elaborada por los acuerdos comerciales de los nuevos bloques hegemónicos y a adquirir mayor identidad a través de ello. 


\section{J.- El Acentuamiento de la Cultura del Desperdicio. Así como en el} terreno productivo para conservar el precio de las mercancías la ley de la oferta y la demanda del mercado ha obligado permanentemente a desperdiciar miles de toneladas de productos en nuestro país plagado de carencias vitales ${ }^{(14)}$; de igual forma la aplicación de los principios del mercado al campo de la conciencia ha obligado a producir a través de las industrias culturales las ideologías del desperdicio más rentables, y a sacrificar los valores más importantes que nos constituyen como comunidad, memoria y Nación en la medida en que no sean altamente lucrativos en términos monetarios y de corto plazo, o que se opongan al crecimiento del mercado. Es decir, en la sociedad mexicana regida exclusiva o mayoritariamente por los principios de la oferta y la demanda, el mercado está liquidando "naturalmente" a todas aquellas formas culturales que son "ineficientes" para respaldar e impulsar el proceso de sobre acumulación y super consumo social y fomenta a las que sí permiten su expansión material.

(14) Por ejemplo, mientras a nivel de desarrollo material en la década de 1990 en el país existió un altísimo déficit lechero de más de cinco millones de litros anuales que nos llevó a importar sólo en 1992 más de 150.000 toneladas de leche en polvo. Una desnutrición crónica en más del $50 \%$ de la población económicamente activa y en el $40 \%$ de los niños provocando la muerte anual de 40 mil infantes en México (Esta realidad se ha dado a tal extremo en algunas regiones de la República, que por ejemplo, en Yucatán por cada cien mil niños que nacen mueren 92 por desnutrición. Un porcentaje más elevado que en Haití y en Guatemala). Un bajo rendimiento escolar por el déficit de peso y la aguda hambre que se presenta en los escolares. Una anemia en seis de cada diez mexicanos y una pobreza extrema en más de 17 millones de personas, etc. Deficitaria en 5 millones de lts. la producción lechera nacional, Excelsior, 21 de noviembre de 1991; Importará México 150 mil toneladas de leche en polvo, El Financiero, 11 de febrero de 1992; 41 millones de mexicanos sin acceso a los mínimos esenciales de nutrición, El Financiero, 15 de octubre de 1991; Están desnutridos 40 \% de los niños mexicanos, Excelsior, 6 de diciembre de 1991; Cada año mueren por enfermedad 40.000 mil niños en México, Excelsior 24 de diciembre de 1991; Mueren por desnutrición 92 de cada cien mil niños en la Zona Centro Yucateca: PN, Excelsior, 18 de marzo de 1992; 31 \% de los niños en el D.F. en edad preescolar padecen déficit de peso, Uno Más Uno, 4 se marzo de 1992; 41 millones de mexicanos sin acceso a los mínimos esenciales de nutrición, El Financiero, 15 de octubre de 1991; Padecen anemia 6 de cada diez mexicanos, afirman especialistas, Excelsior, 21 de octubre de 1991.

En ese mismo período de aplicación de las Leyes de la Oferta y la Demanda en el país las empresas nacionales despilfarraron o destruyeron en 1991 más de 2.000 toneladas de frutas en Chilpancingo, Guerrero; 40 toneladas diarias de tomate y calabaza en Tulancingo, Hidalgo; cientos de toneladas de azúcar en Guadalajara, Jalisco; 35 mil toneladas de soya en Culiacán, Sinaloa; 15 mil toneladas de jitomate en Morelos; 16.800 toneladas de tejocote en el centro del país; 800 toneladas diarias de frutas y legumbres en la Central de Abastos del Distrito Federal, etc., para ser industrias eficientes y conservar los precios competitivos de los productos que exige la nivelación de los mercados. Por día se hechan a pierden 40 toneladas de tomate y calabaza en Tulancingo, Excelsior 6 de septiembre de 1991; Se pudren 200 toneladas de frutas cosechadas en Guerrero, Excelsior 20 de septiembre de 1991; Sobreoferta azucarera en México: Dos millones de toneladas, Excelsior, 21 de septiembre de 1991; Nadie compra a labriegos sinaloenses 35 mil toneladas de soya: Crisantes Enciso, Excelsior, 14 de octubre de 1991; Quince mil toneladas de jitomate perdidas en Morelos, Excelsior, 20 de octubre de 1991; Se desperdician 16, 801 toneladas de tejocote por año, Excelsior, 11 de noviembre de 1991; Tiran al día 800 toneladas de frutas y legumbres, Uno Más Uno, 5 de noviembre de 1991; Sin abasto nacional, Morelos importa jitomates: S Aguilar, Excelsior, 20 de marzo de 1992. 
K.- La Producción de la Cultura Chatarra. El proceso neoliberal de mercantilización extrema de la cultura y de la comunicación ha funcionado bajo la tendencia de producir, exclusivamente, aquella conciencia, educación, tradición e idiosincrasia que sea funcional para incrementar el proyecto de acumulación de capital, especialmente, a escala mega transnacional; y ha marginado la construcción de las políticas culturales orgánicas que urgentemente requiere nuestro proyecto de desarrollo natural. De esta manera, podemos decir que al acercarse el fin del siglo XX, el proyecto "modernizador" introducido al país ha formado intensivamente una nueva "Cultura Chatarra" de la expansión del capital y una reducción de la "Cultura de la Vida y de la Humanización" que tanto requiere nuestra sobrevivencia nacional. Esto debido, a que desde los criterios monetaristas de la modernidad, el impulso de la Cultura de la Vida y de la Humanización no es una actividad lucrativa que valga la pena fomentarla, a menos que el proyecto de desarrollo material llegue a fases críticas en las que el deterioro humano y social avance tanto que se establezca en contradicción con la tasa de producción y concentración de la riqueza.

L.- La Expansión de la Cultura Parasitaria. Con la aplicación del Tratado de Libre Comercio sobre nuestra estructura cultural se ha fortalecido a través de los medios masivos de difusión la producción de una "Comunicación Parasitaria" que nos lleva a saber cada vez más del gran mundo externo y cada día menos de nosotros como Nación, comunidad y como personas. Dicha cultura parasitaria refuerza en grandes dimensiones la difusión intensiva de los contenidos publicitarios, la información secundaria, la violencia temática, el consumo exacerbado, la invasión de la privacía, la banalización de la realidad, la imposición mental del principio de la ganancia a toda costa, la frivolidad informativa, la cosmovisión hollywodense de la vida, etc., que nada tienen que ver con la resolución de nuestras fuertes necesidades estructurales de crecimiento material y espiritual que tenemos que cubrir como pueblo y civilización para sobrevivir.

M.- El Quiebre de Cosmovisiones Nacionales. Así como con la aplicación de las leyes del mercado al campo económico durante los preparativos para el ingreso al Sistema General de Aranceles y Comercio (GATT) y el acceso al Tratado de Libre Comercio, produjeron una gran quiebra de la industria electrónica, metal mecánica, agricultura, textil, plástico, alimentos, tejido, mueblera, calzado, restaurantera, de la transformación, el pequeño comercio y muchos otros más; ahora con el reinado creciente de los principios del mercado en el terreno cultural tenemos que preguntarnos, ¿ Cuáles son las cosmovisiones, las ideologías y los valores culturales propios de la cohesión e identificación de nuestra civilización nacional que ya han quebrado o desaparecerán ante la 
producción de la enorme cultura parasitaria que produce el proyecto modernizador de acumulación material a escala super transnacional a través de las industrias comunicativas?.

N.- La Comunicación Salvaje. Al estar los procesos culturales del país crecientemente regidos básicamente por los principios de la economía de mercado y no por otras racionalidades sociales más equilibradas, hemos sido conducidos como sociedad hacia un sistema de comunicación salvaje que ha producido silenciosamente frente a nuestras narices una enorme crisis cultural, ética y moral. Proceso de comunicación que se ha caracterizado por privilegiar lo superfluo por sobre lo básico; el espectáculo por sobre el pensamiento profundo; la evasión de la realidad por sobre el incremento de nuestros niveles de conciencia; la incitación al consumo por sobre la participación ciudadana, el financiamiento de los proyectos eminentemente lucrativos por sobre los humanistas, la cosificación de nuestros sentidos por sobre la humanización de nuestra conciencia, la homogeneización mental por sobre la diferenciación cultural, la mentalidad del desperdicio por sobre las actitudes sustentables, etc.

Ñ.- Dificultades Para Construir Las Culturas de la Sobrevivencia. La aplicación de los principios de mercado sobre el proceso de funcionamiento de la comunicación colectiva dentro de la nueva fase de apertura y globalización cultural, ha significado que la opción para construir vía la televisión y otros medios de comunicación y cultura una mentalidad colectiva de carácter preventivo o correctivo frente a nuestros grandes problemas de desarrollo nacional como son la protección ecológica, la producción de alimentos, la atención a los sectores marginados, la promoción de la mujer, la aceptación de los grupos indígenas que son los fundadores de este territorio, la conservación de especies naturales, la asimilación de la diferencia, la atención de los ancianos, el combate a la erosión de la tierra, la tolerancia a la biodiversidad, el respeto a la diferencia, la humanización de las ciudades, etc., en una idea, el impulso a una cerebralidad social más desarrollada en favor de la conservación de la vida y no de la muerte; cada vez será más difícil lograrla vía las industrias culturales. Esto debido a que éstas son acciones sociales poco rentables para las leyes del mercado que progresivamente gobiernan más el proyecto de los medios públicos ${ }^{(15)}$.

En este sentido, podemos pensar que debido a que la nueva forma de financiamiento que plantea el modelo neoliberal lleva a que los medios gubernamentales se comercialicen más, y por lo tanto, sean los patrocinadores quienes

(15) La primera competencia que debemos ganar debe ser ante nosotros mismos: Alvarez Lima, Uno Más Uno, 11 de diciembre de 1988. 
determinen el contenido de transmisión de los canales, cada vez más, ha sido más difícil promover una "cultura de desarrollo social" desde estos, pues el esquema de sostenimiento de dichas empresas ha buscado crecientemente la obtención de la máxima ganancia monetaria, a corto plazo.

O.- El Debilitamiento Cultural del Estado Mexicano. Ante el panorama de creciente globalización cultural que ha experimentado la sociedad mexicana, debemos tener presente que por la irresponsabilidad que se mostró al no planificar con fines colectivos el uso de los medios electrónicos en las últimas 3 décadas, la falta de voluntad política para formar desde los canales masivos una cultura para el desarrollo, la debilidad de los gobiernos pos cardenistas para defender la cultura nacional, la complicidad de las autoridades públicas ante la penetración del proyecto transnacional en el terreno psíquico, la desarticulación global que vive el proyecto cultural gubernamental y el retiro sustancial de la presencia del Estado del campo de la comunicación colectiva para que esta sea conducida mayoritariamente por el mercado; hoy el Estado Mexicano ha perdido un enorme terreno para formar, a través de las industrias electrónicas, un fuerte nacionalismo, una sólida identidad y cohesión nacional que sirvieran como punto de despegue para el proyecto de crecimiento interno.

Ante esta realidad comunicativa observamos cotidianamente la presencia de un Estado Mexicano crecientemente más débil, pues no cuenta con un proyecto espiritual para la rectoría de los medios de comunicación electrónicos y de la cultura nacional, sino que el mismo los ha abandonado, mayoritariamente, a los caprichos de las "libres fuerzas del mercado" interno y externo. Por ello, ante la privatización progresiva y el financiamiento crecientemente mercantil de los medios de comunicación públicos, hoy somos cada vez más testigos de la derrota del proyecto cultural del Estado y de la sociedad civil en el terreno cerebral para mantener y ampliar el programa de identidad y democratización nacional a través de la superestructura audiovisual de la República.

Por consiguiente, se puede pensar que la dirección cultural de la sociedad mexicana, especialmente, de las clases medias metropolitanas, ha sido realizada, cada vez más, desde las industrias audiovisuales, particularmente, de carácter transnacionales. Situación que en la medida en que se consolide llevará al país a una mayor dependencia estructural del exterior y en algunos casos a la parálisis cultural del proyecto de conciencia interna de nuestra nación, pues crecientemente conoceremos más sobre lo secundario y no sobre lo central para nuestro desarrollo. Realidad que en el grado en el que se afiance acentuará nuestra crisis nacional, y por consiguiente, ahondará nuestro estado generalizado atraso e infelicidad humana.

En este sentido, desde este horizonte presenciamos que contrariamente a las tesis modernizadoras del Estado Mexicano que han planteado que éste se desre- 
gula y se privatiza para ya no ser más un Estado propietario, sino una entidad orientadora y directora de la sociedad; en la práctica constatamos que en el terreno cultural el Estado se ha convertido en una realidad progresivamente más endeble que no tiene capacidad para dirigir mentalmente a la sociedad mexicana hacia un proyecto cultural propio, autónomo y de superación de la Especie Humana.

Bajo esta perspectiva, podemos decir "que el México Profundo está de nuevo bajo el riguroso control del México Imaginario que, como pocas veces, ha hecho suyo el proyecto de las potencias dominantes. Sin embargo, ese México Profundo sigue vivo y su contradicción con el México Imaginario no ha desaparecido, sino todo lo contrario se ha agudizado"(16).

De aquí, la importancia central de preguntarnos en el marco de la apertura y globalización mundial i Cuál debe ser el papel del Estado Mexicano para construir una política de comunicación y cultura colectivas que permita el avance de nuestra nación y no la simple subordinación subjetiva al modelo internacional de la acumulación de capital ?.

\section{IV.- Comunicacion social y reforma del estado mexicano.}

No obstante que los medios de información se han convertido en el primer poder y que por décadas ha prevalecido el modelo de comunicación anterior, en términos legales su operación ha quedado históricamente enormemente descuidada por el Estado mexicano y la sociedad civil. Así, durante varias décadas han abandonado su comportamiento a un funcionamiento, por un lado, autocrático, espontáneo e incluso caprichoso de los intereses de los grandes propietarios que los operan; y por otro, a la dinámica de la "Mano Invisible" de los voraces principios de la acumulación mercado, sin una cuidadosa legislación actualizada que normatize dicha operación en favor de los intereses de los grandes grupos sociales.

Cuando más, el Estado Mexicano ha delimitado a nivel constitucional una vaga normatividad para la operación de estos medios, pero sin actualizarla a los grandes desafíos tecnológicos, políticos y sociales de la sociedad mexicana de finales del siglo XX. Esto ha colocado internacionalmente a México como "uno de los siete países con el marco jurídico más atrasados en materia de comunicación, solo equiparable a Libia, Irak, Katar, y Cuba; y por debajo de naciones como Paraguay, Colombia y Guatemala"(17).

Esto constata que la revolución tecnológica dirigida por el mercado ha sido gigantesca y la transformación jurídica sobre el marco comunicativo ha sido

(16) El “México Profundo" sigue vivo, Excelsior, 31 de julio de 1991.

(17) México, entre los siete países con las leyes más atrasadas en materia de comunicación, El Financiero 24 de abril de 1998. 
mínima quedando enormemente retrasada frente al avance de la transformación informativa: El actual marco normativo con el que cuenta la sociedad mexicana en materia de comunicación, corresponde a un contexto de realidad mediática de principios de siglo, o cuando más, de la década de los 40s. De esta manera, las instituciones socializadoras mas importantes de toda la estructura cultural del país para la formación, organización y movilización de las conciencias nacionales, han funcionado durante varias décadas en enormes lagunas jurídicas que han propiciado la realización de todo tipo de abusos, violaciones y deformaciones culturales, económicas, políticas, sociales, informativas y espirituales desde los medios de comunicación electrónicos. Una de las principales deformaciones ha sido la práctica del Poder Ejecutivo para otorgar discrecionalmente las concesiones de radio y televisión nacionales o para el manejo de la información comunitaria que equivale a casi un poder virreinal.

Por ejemplo, la Ley de Imprenta data de 1917 cuando fue promulgada por el entonces presidente Venustiano Carranza en un marco de conflicto social posrevolucionario y conlleva un espíritu represivo hacia la libertad de expresión. Por otra parte, pese a que la radio empieza a funcionar desde la década de los años 30s. y la televisión desde los años 50s., la Ley Federal de Radio y Televisión no se creó hasta el 19 de enero de 1960 con el gobierno del Presidente Adolfo López Mateos y quedó atravesada por el vicio de la discrecionalidad política, especialmente presidencial, para ejercer los procesos informativos. De igual forma, el Reglamento de la Ley Federal de Radio y Televisión y de la Ley de la Industria Cinematográfica Relativo al Contenido de las Transmisiones en Radio y Televisión, no se aplican hasta el 4 de abril de 1973.

Así, las precarias, vacías, contradictorias y obsoletas bases jurídicas en materia de comunicación social con que cuentala Constitución Política mexicana al final del siglo XX, han debilitado la estructura y frontera del Estado mexicano y de la cultura nacional. Con ello, se ha desprotegido los derechos de la población mexicana y se ha beneficiado a la estructura del poder monopólico y transnacional en el país.

Dentro de este marco histórico, con el fin de intentar actualizar dicha normatividad y modernizar la reforma del Estado en materia de comunicación social, de 1994 al año 2000 el gobierno y algunos sectores de la dirigencia privada mexicana en turno organizaron en diversos momentos distintas consultas públicas y acuerdos políticos sobre comunicación y cultura. Entre los principales espacios de participación social que se realizaron por parte del Estado, figuraron, entre otros, los siguientes 11 eventos nacionales e internacionales: La Consulta Popular sobre Medios de Comunicación para la Elaboración del Plan Nacional de Desarrollo 1994-2000, organizado de octubre a diciembre de 1994 por la Presidencia de la República y la Secretaría de Gobernación; la Consulta Pública en Materia de Comunicación Social de la Cámara de Diputados, organizada en junio y julio de 1995 por la LVI Legislatura de la Cámara de Diputados del Congreso de la Unión; la Consulta 
Abierta de la Cámara de Senadores sobre Comunicación Social, organizada por el Senado de la República en septiembre de 1995; la Consulta Pública sobre Política y Legislación Cultural del Consejo Nacional para la Cultura y las Artes (CNCA), organizada en febrero de 1996 por la Comisión de Cultura de la LVI Legislatura de la Cámara de Diputados; la Reforma Política del Estado Mexicano y la Comunicación Social, organizada de enero a agosto de 1996 por los principales partidos políticos y la Secretaría de Gobernación, con el fin de actualizar y renovar a través de todas estas acciones el sistema de cultura y de comunicación colectiva en nuestra nación; el foro denominado Los Desafíos de la Comunicación Social en la Ciudad de México, convocado por la Asamblea Legislativa del Distrito Federal ( ${ }^{\circ}$ Legislatura) el 12 y 13 de marzo de 1998; la I ${ }^{\mathbf{a}}$ Conferencia Internacional sobre "El Derecho de la Información en el Marco de la Reforma del Estado en México" organizada por la Cámara de Diputados de la LVII Legislatura, la Comisión de Radio Televisión y Cinematografía (RTC), la Fundación Konrad AdenauerStiftung, la Universidad Iberoamericana (UIA), la Universidad Autónoma Metropolitana (UAM) y la UNESCO, en el Palacio Legislativo de San Lázaro, del 6 al 9 de mayo de 1998; el Foro de Libertad de Expresión y Responsabilidad Social organizado por la Cámara Nacional de la Industria de la Radio y la Televisión (CIRT) el 20 y 21 de julio de 1998 en el World Trade Center de la Ciudad de México; la Conferencia Internacional Sobre Etica y Autorregulación de los Medios al Fin de Milenio organizada por la UNESCO, la Fundación Konrad Adenauer-Stiffung y Universidad Iberoamericana (UIA) el 21 y 22 de octubre de 1998 en el Palacio de Bellas Artes en México, D.F; la II Conferencia Internacional Sobre los Medios Públicos de Comunicación en el Marco de la Reforma del Estado en México, organizada por la LVII Legislatura de la Cámara de Diputados, la Fundación Konrad Adenauer, la UNESCO, el Consejo Nacional Para la Enseñanza e Investigación de las Ciencias de la Comunicación (CONEICC), FELAFACS, la Universidad Autónoma Metropolitana, la UIA y la Red Nacional de Radiodifusoras y Televisoras Educativas y Culturales del 19 al 21 de mayo de 1999 en el Palacio Legislativo de San Lázaro; y finalmente, la III Conferencia Internacional Sobre Medios de Comunicación y Procesos Electorales. Un Compromiso Para el Futuro, organizada por la LVII Legislatura de la Cámara de Diputados, la Fundación Konrad Adenauer, el Consejo Nacional Para la Enseñanza e Investigación de las Ciencias de la Comunicación (CONEICC), la Federación Latinoamericana de facultades de Comunicación Social (FELAFACS), la Universidad Autónoma Metropolitana (UAM), la Universidad Iberoamericana (UIA) y la Asociación Mexicana de Derecho a la Información (AMEDI) el 3 y 4 de mayo de 2000 en el Palacio Legislativo de San Lázaro.

La presencia de estos todos estos espacios de participación social permitieron la exposición pública de múltiples diagnósticos y propuestas de todos los sectores sociales para la transformación del programa de comunicación y cultura del Estado 
mexicano. Así, a lo largo de la celebración de los 11 eventos públicos nacionales para la discusión del proyecto de comunicación colectiva del país, se presentaron en conjunto más de 15.349 diagnósticos y propuestas de todos los sectores de la sociedad civil, política, gubernamental, empresarial y estatal del la República Mexicana para la transformación del Estado en materia de información colectiva. Dichas propuestas oscilaron desde la instauración del derecho de réplica en los medios, la formación del Código de Etica Periodística, la creación de la figura del Ombudsman de la Comunicación Colectiva, el aprovechamiento democrático del 12,5\% del tiempo oficial en los medios, prohibir la existencia de monopolios comunicativos, suprimir los mecanismos directos y velados de censura, los procesos de autorregulación empresarial; hasta la revisión del otorgamiento de las concesiones, la apertura de los espacios comunicativos para la participación de la sociedad civil, la creación de un Consejo Nacional de Medios de Comunicación, la modificación total de la actual normatividad en materia de comunicación social, la ampliación de la red de medios culturales, el fortalecimiento de los medios de servicio público, etc.

Sin embargo, pese a esta enorme cantidad de participaciones ciudadanas para intentar transformar el sistema de comunicación nacional se ha demostrado que los diagnósticos, las demandas e iniciativas fundamentales de políticas de comunicación que ha presentado la sociedad mexicana para la transformación del Estado nacional, vía los Foros, los Seminarios y las Consultas Públicas, han sido negadas, menospreciadas, desconocidas y marginadas por la esfera del poder. Con ello, una vez más, vuelve a surgir la profunda desilusión y desencanto de la sociedad civil para considerar que los espacios de "apertura" que ha creado el Estado sean los conductos viables para la transformación de los medios de comunicación nacionales.

No obstante en esta gran tendencia cancelatoria del gobierno sobre los planteamientos civiles en materia de comunicación se observa que de todo el cúmulo de propuestas presentadas por la sociedad mexicana en los múltiples foros abiertos de consulta pública, la única iniciativa que parcialmente prosperó, y con muchísimos obstáculos, fue la propuesta de "Ley Federal de Comunicación Social y el Proyecto de Ley Reglamentaria de los Artículos 6 y 7 Constitucionales en Materia de Libertad de Expresión y Derecho a la Información" preparada por la Comisión de Radio Televisión y Cinematografía (RTC) de la XLVI Legislatura de la Cámara de Diputados del Congreso de la Unión y que fue retomada por la XLVII Legislatura del Congreso para discutirla y perfeccionarla ${ }^{(18)}$.

(18) Iniciativa de Ley de Comunicación Social. Proyecto de Ley reglamentaria de los Artículos $6^{\circ}$ y $7^{\circ}$ Constitucionales en Materia de Libertad de Expresión y Derecho a la Información, Comisión de Radio Televisión y Cinematografía (RTC) de la XLVII Legislatura, Honorable Cámara de Diputados, Congreso de la Unión, México, D.F., marzo de 19981. 
Sin embargo, para evitar avanzar en este terreno estratégico de reglamentación al Derecho a la Información el sector mas conservador del Estado y los empresarios de los medios de información en conjunto crearon a través de sus propios canales de difusión masiva campañas permanentes de satanización y boicot a dichas iniciativas democráticas de la sociedad civil, argumentando artificialmente la existencia de un conflicto entre libertad de expresión y reglamentación de la misma.

Dicha campaña constó de dos fases de desinformación y manipulación. La primera fase se concentró en no difundir por los medios de información masivos aquellas posiciones ideológicas contrarias a las tesis de la autorregulación. En los pocos casos en que se consideraron, siempre se relegaron a lugares de 5 o 6 nivel informativo para que se perdieran en el océano de datos que diariamente se transmitieron.

La segunda fase consistió en una repetitiva presentación colectiva de juicios y valores a priori que descalificaron de entrada el intento de propuesta legislativa, sin pasar por la discusión o reflexión pública. Así, se señaló reiteradamente que las iniciativas regulatorias del Derecho a la Información son fascistas, que amordazan la libertad de comunicación, que son paralizantes de la iniciativa humana, que evitan la libre competencia, que censuran el libre fluir del pensamiento, que se intenta controlar a los medios, que se busca reprimir a los periodistas y comunicadores, que son leyes mordazas, etc, con el fin de evitar que se regularan por el interés colectivo, los privilegios tan desmesurados con los que cuentan los propietarios de los medios dentro de la caduca legislación mexicana de final de siglo. A diferencia de estrategias anteriores, en esta segunda etapa se incorporaron un conjunto de comunicadores de reconocido prestigio nacional para darle más peso a la ingeniería desinformadora y calumniadora, y evitar que los medios de información colectivos fueran regidos por la ley ${ }^{(19)}$.

En éste sentido, así como el sector bancario practicó una acción de "anatocismo" económico al cobrar intereses sobre intereses; con el despliegue de esta campaña desinformadora y calumniadora sobre la regulación del Derecho a la Información, los concesionarios de los medios de difusión colectiva en México practicaron un "anatocismo comunicativo" desde el momento en que aprovecharon el poder persuasivo de sus canales de información colectiva para conservar la estructura de poder de todos sus medios ${ }^{(20)}$.

(19) Virgilio Caballero, Etica y Regulación de los Medios al Final del Milenio, Conferencia Internacional: "Etica y Autorregulación de los Medios a Fin de Milenio", Fundación Konrad Adenauer Sitiffung, Universidad Iberoamericana y UNESCO, México, D.F., Palacio de Bellas Artes, Sala Manuel M. Ponce, 22 de Octubre de 1998.

(20) Marcos Rascón, Los Medios de los Medios. (Otro Caso de Anatocismo), La Jornada, 15 de octubre de 1998. 
De esta forma, ninguno de los reclamos básicos de la sociedad civil han sido contemplados en el proyecto comunicativo del mercado y del poder al final del siglo XX. Con ello, el Estado ha desconocido permanentemente que en la sociedad de final de milenio los medios de información colectivos son la base de existencia de lo público, y que por consiguiente, dichas instituciones deben ser normados por la sociedad en su conjunto, y no sólo por los intereses fenicios del mercado o los ambiciosos e ilimitados intereses del poder.

Así, la no transformación de esta realidad mediática ha modificado la estructura y la frontera del Estado mexicano y de la cultura nacional creando una nueva realidad en la esfera del poder que es el Estado diluido y la cultura light. Estado y mentalidad colectiva que cada vez son bases mas débiles para crear los fundamentos de una civilización y cultura para la sobrevivencia social.

Ante esta monumental pobreza de rescate del espíritu del "México Profundo" por parte de la estructura de gobernabilidad nacional a partir de las consultas públicas sobre comunicación social, es necesario preguntarnos, por ejemplo, i Dónde quedó la solicitud ciudadana de revisar el otorgamiento y la revocación de las concesiones de los medios de comunicación, especialmente de los electrónicos ?. ¿ Por qué no se consideró la formación de la figura jurídica del Omdbusman de la comunicación colectiva ?. ¿ Por qué se marginó la revisión de la legislación referente a la constitución de los super monopolios comunicativos que se volvió a encarnar con la bárbara fusión entre TELMEX y TELEVISA ?. ¿ Por qué no se abordó la urgente necesidad de abrir más espacios de participación democráticos en los medios de comunicación ?. ¿ Por qué se olvidó la formación del Código de Etica Profesional de los comunicadores ?. ¿ Por qué se marginó la iniciativa del Derecho de Réplica solicitada ampliamente por la sociedad mexicana desde hace varias décadas para evitar los abusos informativos de los propietarios de los medios ?. ¿ Dónde quedó la propuesta de formar un Consejo Plural de Comunicación Social que supervisara el funcionamiento de los medios de información en nuestro país ?. ¿ Por qué se desconoció la petición colectiva de emplear el 12,5 $\%$ del tiempo, oficial en los medios de comunicación de forma más democrática y racional ?.

¿Dónde quedó la inquietud de otorgar con toda transparencia los recursos gubernamentales y paraestatales de apoyo financiero a los medios de comunicación ?, ¿ Por qué se descartó la propuesta de crear una Red Nacional de Televisión Cultural a partir del empleo de la infraestructura de los sistemas estatales de comunicación establecidos en cada entidad y del otorgamiento de dos frecuencias en la banda UHF y del aprovechamiento de los tres canales de cable que por ley tiene derecho el Estado en cada una de las entidades federales ?, ¿ Dónde quedó la iniciativa educativa de incorporar en la Ley Federal de Educación, en los Libros de Texto Gratuitos, en el Libro del Maestro y en los planes de estudio de las Escuelas Normales una normatividad y un análisis sobre el papel educativo de los 
medios de comunicación ?. ¿ Por qué se olvidó la sugerencia de realizar las adecuaciones legales correspondientes para salvaguardar las particularidades regionales y la identidad nacional ?, ¿ Dónde quedó la idea de apoyar el proyecto de la descentralización y regionalización cultural y comunicativa del país ?., ¿ Por qué se sepultó la propuesta de legislar sobre la obligatoriedad y solvencia de una certificación publica del tiraje real y de la circulación de los periódicos y revistas, en favor de una mejor competencia en el mercado y de la claridad y veracidad con respecto a los lectores ?, etc.

Ante ello, podemos decir que todos estos espacios públicos generados por el gobierno modernizador de finales del siglo XX, más que servir para el enriquecimiento y la ampliación de las políticas de comunicación de un proyecto de crecimiento democrático y humanizador, operaron como un sistema de legitimación de los intereses verticales del Estado y del poder en este terreno. En este sentido, una vez más, la comunidad nacional vivimos una gran estrategia gubernamental de burla y manipulación social para reforzar el proyecto autoritario del Estado y del poder en materia de información colectiva, con lo que se ha acrecentado el desencanto y la frustración de la sociedad civil para creer en el Estado como una plataforma desde la cual se puedan transformar los medios de difusión.

Así, a principios del nuevo milenio se vuelve a repetir la misma historia de petrificación y antidemocracia del Estado mexicano en materia de comunicación social que la sociedad mexicana ha vivido desde la década de los años 70s. Hay que recordar que el resultado de todas las consultas populares desde 1970 a la fecha han concluido con el mismo resultado de "no encontrarle la cuadratura al circulo", y por lo tanto, no transformar el actual marco normativo de la comunicación social, permitiendo que continúe gobernando el mismo orden cerrado, viciado, discrecional e impune de los procesos comunicativos.

En este sentido la estructura de la comunicación social vigila, juzga y fiscaliza todas las áreas del funcionamiento de nuestra sociedad; pero es el único poder que en la práctica política no queda supervisado por el interés colectivo.

Esta realidad refleja que al concluir el siglo y comenzar el nuevo milenio en el campo de la comunicación y la cultura continuamos estando ante un Estado feudal, sordo, insensible y prepotente que no comprende los latidos del corazón del México Profundo que demanda democracia, apertura y pluralismo en materia de comunicación social. Estado Feudal mexicano que como en la Edad Media, vía el rígido control de los medios de comunicación públicos, no permite la participación de los grandes grupos en los procesos masivos de construcción de la conciencia social.

Incluso, la rigidez histórica del Estado mexicano para no transformar la estructura de medios de comunicación nacionales ha sido tal que, en términos generales, en la década de los noventa, la transición a la democracia se ha dado 
a pesar y en contra del sistema de medios de comunicación dominantes. Fue hasta que el proceso de democratización empezó a rebasar a las estructuras de gobernabilidad tradicional, cuando los medios retomaron este proceso, pero no para fortalecerlo centralmente, sino para aumentar su rating y no quedar fuera de la dinámica exitosa del mercado.

En este sentido, podemos decir que al no considerar los principales diagnósticos y propuestas que presentó el despertar del sector civil para transformar la esfera pública de la conciencia nacional vía los medios de comunicación colectivos, el Estado mexicano no renovó su proyecto de comunicación colectiva para enfrentar los desafíos elementales de la sociedad mexicana de finales del siglo XX. Con ello, el Estado mexicano "moderno" cuenta con menos bases de representatividad social, y en consecuencia, es cada vez menos rector nacional en el campo de la moral colectiva, acelerando con ello su debilidad y descomposición estructural.

De esta forma, aunque el gobierno ha creado una gran campaña propagandista para difundir que el Estado mexicano se ha transformado en todos sus niveles, hasta el momento podemos afirmar que la reforma del Estado mexicano no se ha realizado, pues por falta de voluntad política no se ha establecido un nuevo pacto de relación entre medios de comunicación y sociedad a través de la creación de una nueva normatividad jurídica sobre los mismos. Con ello, todo el proceso de la reforma del Estado mexicano ha quedado profundamente vulnerada porque la democratización de la comunicación es el principio que democratiza todos los otros procesos de la vida cotidiana y colectiva.

Debemos de considerar que para que se pueda consolidar la reforma del Estado mexicano se requiere la indispensable transformación democrática profunda de las estructuras de información y comunicación masivas, ya que son estos espacios los que se han convertido en el Primer Poder contemporáneo desde el cual se organiza, moviliza, articula y dirige, diaria y principalmente, de manera colectiva a los habitantes de la nación ${ }^{(21)}$. Debido a su peso central sobre la dirección de la nación, en una sociedad democrática los principales poderes siempre deben estar supervisados y reglamentados por la sociedad en su conjunto.

En la actualidad, no puede existir un gobierno moderno y avanzado, sin la transformación democrática e integral de sus instituciones de cultura y medios de comunicación colectivos, ya que es a través de ellos, como se realiza cotidianamente la principal forma de conducción, organización y participación colectiva en comunidad. Es desde la democratización del sistema mediático

(21) Ikram Antaki, conceptos expresados por la escritora en la conferencia de prensa, foro sobre Libertad de Expresión y Responsabilidad Social, Cámara Nacional de la Industria de la Radio y la Televisión (CIRT), World Trade Center, México, D.F., 21 de julio de 1998. 
como se puede reconstruir el tejido democrático del país. Si los medios son concesiones que la sociedad le entrega al Estado como rector de lo público para que las supervise en base al bien común, y éste las entrega a concesionarios, el Estado esta obligado a vigilarlas para que sirvan para el crecimiento de la sociedad y no de su estancamiento.

Debemos tener presente que la construcción de la democracia no se puede alcanzar sin la profunda democratización de los medios de información: democracia social es sinónimo de apertura y pluralidad de los canales de información. Por consiguiente, un Estado moderno tiene que generar una sociedad permanente y ampliamente informada sobre sus problemas fundamentales y no sobre las simples "frivolidades modernizantes" que crea el ciclo de la moda occidental o las curvas del raiting. De lo contrario, la falta de información pública sobre los grandes problemas comunitarios o nacionales, tarde o temprano, produce gigantescos atrasos y conflictos sociales estructurales.

De esta manera, gracias a la confianza inicial que les otorgó la sociedad mexicana los medios han alcanzado la concentración de un enorme poder económico-político por encima de la voluntad de la sociedad y el Estado, y se han convertido en un poder casi autónomo que tiende a funcionar al margen de las normatividades colectivas. Así, casi se han convertido en reyes autocráticos que se oponen a someterse a la supervisión de la voluntad de la comunidad nacional. Bajo esta perspectiva, podemos afirmar que las débiles, vagas, contradictorias y anacrónicas bases legales en materia de comunicación social con que cuenta la Constitución Política mexicana al final del siglo XX, han privilegiado los intereses de la vieja estructura de poder por sobre los fundamentos jurídicos de la nación que permitan construir una Nueva República y fortalecer la democracia.

Con la autorización deliberada de estas omisiones político-legales en la década de los 90s. el Estado mexicano permitió, una vez más, que los voraces intereses del capital y del poder que permanentemente construyen en nuestro país una cultura salvaje y de la desmovilización social vía el funcionamiento libertino de los medios de comunicación, sean protegidos por el actual marco normativo de las industrias culturales. Así, cada vez más la dinámica de las leyes del mercado rebasan los intereses colectivos de nuestro Estado Nación para fortalecer el proyecto de desarrollo equilibrado y promueven la realización de las bárbaras leyes del capital en el campo de la cultura y la conciencia social.

Ante este horizonte de cerrazón estatal para la democratización informativa, nos enfrentamos al delicado panorama político en el que los grandes grupos sociales no cuenten con espacios de expresión dentro de estos para expresar sus necesidades, problemáticas, demandas y soluciones. Frente a ello, se observa la tendencia creciente de que los movimientos sociales en emergencia continúen creando sus propios procesos clandestinos de comunicación colectivos, que derivarán, tarde o temprano, en la construcción de un nuevo Estado Ampliado paralelo 
al oficial, con el consecuente acrecentamiento de nuestra crisis de hegemonía nacional. Ejemplo de ello han sido el surgimiento temporal de los medios contra estatales como "Televerdad", "Radio Vampiro" y "Radio Pirata" y las intervenciones guerrilleras que se dan a través de Internet.

El conjunto de estos indicadores políticos reflejan que al iniciar el siglo XXI la sociedad mexicana está atravesada por cuatro grandes tendencias políticas comunicativo-culturales de masas:

En primer término, la comunidad nacional termina con un Estado débil en el terreno de las políticas de información, pues ha renunciado a no ejercer su función rectora en el campo de la comunicación colectiva para dejar su rectoría en manos de las fuerzas del mercado que sólo protegen los intereses del gran capital en esta área. En este sentido, el Estado mexicano a través de su postura de la autorregulación ha optado por defender los intereses del proyecto de super concentración de riqueza y no los derechos y garantías individuales más elementales que los ciudadanos han demandado desde los años 60s.

En segundo término, la estructura mental de la sociedad mexicana termina profundamente atravesada por un proyecto muy fuerte de cultura, comunicación, y espiritualidad colectiva conducido por las voraces fuerzas del mercado que fomentan la dinámica del "Dejar Hacer y Dejar Pasar Cultural" a costa de los que sea y sin restricción alguna; y que es ampliamente protegido por las ideologías y los valores de plástico que ha introducido la modernidad con la anuencia de los gobiernos nacionales en turno. Dicho proyecto, basado en la lógica de la acumulación de capital a escala planetaria, promueve intensamente la expansión de la Cultura de la Muerte que está cimentando silenciosamente frente a nuestras narices el nuevo derrumbe de nuestro país.

En tercer término, el conjunto de los partidos políticos mantienen una posición de despreocupación e irresponsabilidad por el problema de las políticas nacionales de comunicación, salvo en los momentos electorales que pelean el espacio y tiempo de exposición de sus candidatos en los medios para ganar votos o en coyunturas políticas muy especiales que les permiten legitimarse u obtener simpatías ante la opinión pública. El resto del año o del ciclo político ignoran esta realidad vertebral para construir la conciencia colectiva

Y finalmente, en cuarto término, aunque existen cada vez más brotes de iniciativas aisladas en la sociedad civil, el cerebro de la sociedad mexicana queda debilitado grandemente por la ausencia de un proyecto público orgánico de transformación y uso democrático de los medios de comunicación para el desarrollo equilibrado de la nación, y sin sólidas fuerzas o frentes sociales reales que permitan su surgimiento desde la gran sociedad civil organizada.

Es por ello, que ante el próximo gobierno es necesario repensar qué hacer en términos políticos para crear otro proyecto colectivo de comunicación social que sí rescate el espíritu de estos planteamientos esenciales para democratizar a la 


\section{V.- ¿Qué hacer?: Hacia una nueva política de comunicación social en el marco de la globalización.}

El modelo de desarrollo modernizador que gradualmente ha adoptado México al final del siglo XX con el Tratado de Libre Comercio en sus estructuras culturales para incorporarse al nuevo orden mundial surgido después de la guerra fría, basado mayoritariamente en el supuesto del "poder regulatorio mágico" de la "Mano Invisible" del mercado para dirigir la participación social; ha comprobado en una década sus enormes limitaciones y las bárbaras deformaciones humanas que ha producido. Ejemplo de ello, han sido la drástica devaluación del peso, la brutal fuga de capitales, el colapso agropecuario, la bárbara destrucción ecológica en todo el territorio nacional, la incontenible corrupción, el agudo desempleo, la marcada reducción de nuestro nivel de calidad de vida, el aumento de la incredulidad institucional, la crisis de esperanza de la juventud, el aumento de la violencia, etc.

Por ello, después del fracaso de dicho modelo ahora se requiere la búsqueda e implementación de nuevas políticas, especialmente de cultura y comunicación, para lograr la participación de la sociedad a través de otros procesos de información y contribuir, con ello, a resolver las agudas contradicciones mentales que limitan el crecimiento equilibrado de nuestra nación ${ }^{(22)}$.

(22) Algunas de las contradicciones que se reflejan entre el nivel de conciencia y el proyecto de desarrollo nacional se manifiestan en la oposición creciente que se establece entre formación de la conciencia nacional y la difusión de los contenidos de los medios de comunicación, particularmente electrónicos, en México. En este sentido, debido a la cultura paralela que han formado los medios electrónicos de difusión en México en las últimas décadas, se observa que los niños mayores de seis años conocen más la información televisiva que la transmitida en la escuela primaria u otros órganos culturales. Por ejemplo, en el terreno de la realidad nacional el $77 \%$ de los pequeños retienen más frases como "La chispa de la vida" o "Recuérdame" y sólo el $49 \%$ conserva otras como "iViva la Independencia! o "La solución somos todos" o "El respeto al derecho ajeno es la paz". De igual manera, mientras que casi la totalidad de los niños $(92 \%)$ retiene la imagen del Gansito Marinela, menos de dos terceras partes (64\%) identifica la Columna de nuestra Independencia o al cura Hidalgo. El 63\% de los niños asocia fácilmente el tema de la tarjeta de crédito "Carnet" y sólo el $43 \%$ reconoce la frase "El respeto al derecho ajeno es la paz". En resumen, observamos que de cada diez personajes que los niños identifican, sólo tres son de la historia de México.

En el campo de la historia, el $67 \%$ de los niños identifican los días y horarios en que se transmiten sus programas favoritos de televisión, mientras que sólo el $19 \%$ enuncia las fechas en que ocurrieron los acontecimientos más significativos de la historia nacional. Los super héroes de la televisión como "La mujer maravilla", son más conocidos por los pequeños (98\%) que los héroes de la Revolución mexicana (33\%). "El Chapulín Colorado" es más evocado por los infantes (96\%) que los Niños Héroes de Chapultepec (82\%). "Supermán" está más presente en la mente de los pequeños $(97 \%)$ que Don Benito Juárez.

En materia religiosa, no obstante que nuestra sociedad es acentuadamente católica, más de la mitad de los niños $(56 \%)$ conoce el día en que se transmitía "Hogar dulce hogar", mientras que sólo el (36\%) recuerda el día en que se celebra la Navidad. Mientras el 55\% de los niños puede decir qué día se difundía el programa "Mis huéspedes", sólo el 32\% sabe la fecha en que se celebra la fiesta de la Virgen de Guadalupe. Los pequeños identifican mejor el logotipo de "Sabritas" (86\%) que una ostia (46\%). 
En este sentido, es fundamental sustituir dentro del contexto de la modernidad la idea de crear un "Estado Mínimo" o "Ultra Mínimo" en el área cultural de México a través de la adopción indiscriminada de la política del "laissez faire informativo"; para ahora introducir la concepción estratégica del "Nuevo Estado Básico para la Sobrevivencia Social” sin el cual no podrán construirse un orden civilizatorio superior que mantenga las condiciones elementales de la convivencia en comunidad, especialmente, en la medida en que en el país somos crecientemente sociedades de masas cada vez mayores ${ }^{(23)}$. "Nuevo Estado Básico para la Sobrevivencia Social" que no se limite a ejercer la labor meramente de vigilancia policíaca, de atención a las urgencias inmediatas, de cubrir el servicio de recolección de basura, asistencia de los bomberos, etc., sino sobretodo que haga posible la participación democrática de la población en los procesos de creación de cultura y comunicación colectivos. Es decir, una comunicación de Estado al servicio del hombre y no el hombre al servicio del mercado, vía la información.

Debemos recordar que ya en el siglo XIX las profundas alteraciones que produjo el funcionamiento autónomo del mercado autoregulado en México generaron tantas contradicciones sociales que dieron origen al capitalismo salvaje e hicieron indispensable el surgimiento del Estado Benefactor para corregir dichos antagonismos insostenibles. Por ello, desde principios del siglo XX se intentó sustituir la lógica de la supremacía del mercado, por otra lógica más sensible y humana de justicia y participación social ${ }^{(24)}$.

En el área cívica, el $87 \%$ de los infantes conoce los días en que se transmiten los programas cómicos y sólo el 13\% sabe la fecha en que toma posesión el Presidente de la República. Sólo el $8 \%$ conoce la fecha en que el primer mandatario rinde su informe anual, mientras que el $61 \%$ sí puede decir el día y la hora en que aparecen las series fantásticas. El 83\% de los niños identifica el logotipo de los pastelitos rellenos y sólo el $63 \%$ conoce el Calendario Azteca. Mientras que el $81 \%$ de los pequeños evoca el logotipo de los productos "Marinela", sólo el 66\% identifica el escudo nacional. Las tres cuartas partes (77\%) de los niños identifican la imagen de Chicles Adams y menos de una quinta parte (17\%) reconoce el Monumento a la Revolución. Finalmente, el logotipo de los chocolates "Carlos V" es más reconocido (77\%) que el Monumento del Angel o la columna de la Independencia (40\%). La Televisión y los Niños. Conocimiento de la Realidad Televisiva Vs. Conocimiento de la Realidad Nacional, Cuadernos del Consumidor, Instituto Nacional del Consumidor (INCO), México, D.F., noviembre de 1982.

Este problema de identidad se agrava crecientemente en la medida en que se avanza en la aplicación de los principios de mercado del Tratado de Libre Comercio sobre la comunicación colectiva nacional y se acentúa el debilitamiento de la política educativo-cultural del Estado Mexicano.

(23) En el TLC el mercado fijará precios a los básicos, Excelsior, 27 de marzo de 1992; ¿ De qué sirve la democracia si pervive el mercantilismo en América Latina ?, Excelsior, 3 de junio de 1992; Está en duda que el mercado solucionará mágicamente los problemas económicos, El Financiero, 26 de noviembre de 1993.

(24) La lógica del mercado, El Financiero, 4 de agosto de 1992; Regula la existencia de la sociedad, Excelsior, 31 de mayo de 1992; Base del Estado corporativo, Excelsior, 2 de junio de 1992; Intervencionismo del Estado. Orígenes y modalidades del Estado, Excelsior, 3 de junio de 1992; Izquierda y totalitarismo. Orígenes y modalidades del Estado, Excelsior, 4 de junio de 1992; La teoría del Estado. Orígenes y modalidades del Estado, Excelsior, 5 de junio de 1992. 
Incluso, constatamos que las principales naciones que impulsaron el modelo neoliberal del "Estado Mínimo" en los años 80s. como fueron los gobiernos de Ronald Reagan en Estados Unidos y de Margaret Thatcher en la Gran Bretaña, a mediados de la década de los 90s. fueron corregidos drásticamente por los respectivos gobiernos de William Clinton en Norteamérica y de John Major en Inglaterra para fortalecer de nuevo al Estado Benefactor y resolver las grandes contradicciones que produjeron la aplicación irrestricta de las leyes del mercado en estos países. Dicha neointervención del Estado planteó ajustar el rumbo autónomo del mercado a través de una acción mas activa de éste en la gestación de las macro políticas de crecimiento, pero no supone suprimirlo ${ }^{(25)}$.

Es por esto, que ante el nivel límite de evolución en el que nos encontramos como civilización nacional y frente a la creciente realidad de establecer la "Iniciativa del Mercado" en el campo de la cultura y la comunicación colectiva del país, debemos considerar que así como una cantidad de actividades estratégicas para el desarrollo del Estado Mexicano no pueden dejarse en manos del sector mercantil, a riesgo de que desaparezcan como es el caso de la medicina preventiva, la generación del transporte urbano público, el impulsar a la ciencia básica, la producción de infraestructura urbana ${ }^{(26)}$, etc; así tampoco puede delegarse a éste la construcción de una "Cultura Social para la Sobrevivencia Nacional”. Esto debido, a que aunque, paradójicamente, a largo plazo, la planificación cultural es la inversión económica más rentable que existe en México, a corto plazo, no es lucrativa dentro de los criterios de "ganancia pecuniaria" y de corto plazo que establece la actual concepción neoliberal de la vida.

Por ejemplo, en el campo de la física el descubrimiento del "Boscon de Higgs" o el invento del acelerador de partículas mas costoso del mundo "SSC", no pudieron desarrollarse sin la aportación multimillonaria de los Estados de la

(25) El retiro del Estado impone retos capitales al neoliberalismo, Excelsior, 28 de septiembre de 1993; El cambio debe ser garantía de justicia, Excelsior, 28 de septiembre de 1993; La nueva cara del regulador económico, Excelsior, 28 de septiembre de 1993; Peligro el capitalismo salvaje, Excelsior, 2 de noviembre de 1993.

(26) Sí al neoestatismo para guiar y no remplazar al mercado, Excelsior, 13 se abril de 1992; Corrige J. Major a M. Thatcher y fortalece al Estado Benefactor, Excelsior, 15 de julio de 1992; Profundo rechazo en Wall Street a Clinton. Temor a un incremento de tasas de interés e inflación, El Financiero, 13 de noviembre de 1992; El Neointervencionismo Estatal, El Financiero, 23 de noviembre de 1992; Clinton: $i$ Un nuevo Liberalismo Social ?, El Financiero, 24 de noviembre de 1992; Clinton, intervencionista astuto si concilia Estado y mercado, Excelsior, 26 de noviembre de 1992.

La aplicación del liberalismo a ultranza en Estados Unidos durante más de 15 años provocó que una pequeña minoría se enriqueciera desproporcionadamente, mientras la mayoría social se convirtiera en más pobre, sin encontrar en el "paraíso capitalista" la felicidad prometida. De igual forma, la implementación durante varios años de la dinámica de la "mano invisible" en Inglaterra descuidó la educación pública al grado que en 1992 sólo el 34 \% de los jóvenes entre 16 y 18 años gozaban de un sistema de capacitación, contra $47 \%$ en Alemania y $66 \%$ en Francia. El Neoliberalismo continúa haciendo "agua" en Estados Unidos, El Universal, 2 de octubre de 1993. 
Comunidad Económica Europea y del Estado Americano ${ }^{(27)}$. De igual forma, la formación de una cultura ecológica, de una cultura de conservación de las especies que componen la conservación de las cadenas de reproducción de la vida, de una cultura de la defensa de los ancianos, de una cultura del cuidado del Planeta Tierra, de una cultura de la convivencia civil, de una cultura de revaloración de lo nacional, de una cultura de la promoción de la vida, etc. que son niveles de cerebralidad mínimos que requerimos construir y conservar para sobrevivir en sociedad de masas cada vez mayores; tendrán que ser creadas por el Estado y la sociedad civil, ya que para el sector mercantil no es rentable efectuarla.

Ante este panorama de creciente desigualdad comunicativa y espiritual que se establece con la aplicación del modelo de mercado del Tratado de Libre Comercio en nuestra República, es necesario que el Estado mexicano cree las condiciones de otro equilibrio cultural a través de la elaboración de una "Nueva Política de Cultura y Comunicación Social para la Sobrevivencia Nacional", que actualmente no existe y se requiere urgentemente para coexistir. Para ello, hay que considerar que así como en el campo económico el Estado reprivatizó la banca estatal y paralelamente impulsó la banca de desarrollo para apoyar a los sectores más desfavorecidos, o que así como vendió empresas públicas para destinar fondos a los proyectos de equilibrio social vía el "Programa Nacional de Solidaridad" (28); ahora, es necesario que así como ha permitido crecientemente el juego de los principios del mercado en el área cultural, se apoye la dinámica de "Equilibrio de la Comunicación Social" que surge desde las necesidades de expresión y participación ideológica más apremiantes de los grupos mayoritarios del país.

Con ello, se podrán rescatar los aspectos positivos que ofrece la economía de mercado en el campo cultural, como son la eficiencia, la competitividad, la libertad individual, la apertura de mercados, la adopción de nuevos financiamientos, etc.; y al mismo tiempo se aplicarán los contrapesos culturales de nivelación mental necesarios para sobrevivir que no están incluidos en el frío cálculo económico neoliberal. Frente a esto en imprescindible considerar que la práctica del libre juego de las fuerzas culturales y comunicativas, no generan automáticamente

(27) ¿ Realmente debemos confiar todo a la Iniciativa Privada ?: El caso de la Física, El Financiero, 1 de noviembre de 1991.

(28) Liberalismo social, nuestra filosofía; Contra Estatismo y Neoliberalismo absorbente, El Financiero, 5 de marzo de 1992. El liberalismo social, Excelsior, 7 de marzo de 1992; El liberalismo social: Nuestro camino, Uno Más Uno, 8 de marzo de 1992; ¿ Neoliberalismo social ?, Uno Más Uno, 11 de marzo de 1992; Entre la política y la economía. La condición de los serviles, Excelsior, 13 de marzo de 1992; El liberalismo social fortalece la soberanía, Uno Más Uno, $1^{\circ}$ de marzo de 1992; Recursos a los marginados con mecanismos de mercado, Excelsior, 14 de marzo de 1992; Que del liberalismo, Uno Más Uno, 17 de marzo de 1992;_De nuevo sobre el liberalismo, Uno Más Uno, 10 de marzo de 1992; El liberalismo social se vive con el Pronasol, Excelsior, 21 de marzo de 1992; Ni la soberanía es obsoleta, ni existe un modelo único, Excelsior, 22 de marzo de 1992. 
un proceso de comunicación superior; sino que para lograrlo se requiere la presencia y la acción de procesos sociales planificadores, con alto nivel de participación de la sociedad civil ${ }^{(29)}$. Contrapesos planificadores que no sean burocráticos, estatistas, paternalistas o populistas; pero que si vinculen globalmente los principales requerimientos de desarrollo social con la dinámica de producción cultural e informativa.

De lo contrario, los grandes límites naturales, que por sí misma, fija la economía de mercado sobre las dinámicas comunicativas, generarán más contradicciones culturales que las que pretende resolver por la acción de la oferta y la demanda; y que sólo podrán ser resueltas con la introducción de la "Racionalidad de la Comunicación Social" en el campo de lo público. De no construirse esta política de equilibrio en el área comunicativa y cultural, cada vez más, se vivirá el profundo divorcio existente entre necesidades materiales y espirituales de crecimiento social y la formación de la cerebralidad colectiva para resolverlas.

En este sentido, por nuestro propio bien como República, hoy estamos obligados a preguntarnos con todo rigor: En la etapa de la apertura de fronteras $i$ Cuál debe ser la función rectora del Estado en el campo de la comunicación colectiva ?. ¿ Hasta dónde a mediano y largo plazo este modelo de desarrollo modernizador creará una cultura que propicie el verdadero crecimiento de nuestra sociedad o producirá un retroceso del avance del Hombre ?. ¿ Qué acciones culturales debemos de realizar para reforzar nuestra identidad nacional dentro de los marcos de los principios del mercado ?. ¿ Cómo producir una cultura del desarrollo social dentro de la dinámica de la oferta y la demanda ?. ¿ Cómo conciliar las presiones de un modelo económico que deforma la estructura cultural para incrementar sus niveles de acumulación material, con la necesidad urgente de formar una cultura global para la sobrevivencia humana y el respeto a la vida ?. En la fase de globalización del país ¿ Cuáles deben ser los contenidos culturales de una política nacional de comunicación social que propicie que se eleven los niveles de calidad de vida material, comunitaria y espiritual en el México de principios del siglo $\mathrm{XX}$ ?.

Es por ello, que ante el próximo gobierno es necesario repensar qué hacer en términos políticos para crear otro proyecto colectivo de democratización de la comunicación social que permita que los medios de información se orienten hacia el desarrollo de nuestra conciencia para resolver nuestros conflictos de crecimiento; pues el proceso de la globalización mundial nos lleva a la creación de un nuevo orden cultural que modifica los contenidos y las fronteras ideológicas de los actuales Estados nacionales. De no efectuar esto, el alma cultural de nuestra sociedad correrá el gran riesgo de quedar sepultada por los nuevos espejismos de 
la modernidad y sus derivados simbólicos parasitarios de ésta nueva fase del desarrollo de la sociedad capitalista internacional.

De aquí, la enorme importancia que la sociedad civil presione a las Comisiones de Cultura y de Comunicación Social de la Cámara de Diputados del LVIII Período Legislativo para reglamentar con gran profundidad la operación de dichos medios de comunicación, pues en última instancia no se esta legislando sobre simples instituciones de esparcimiento, diversión o información; sino sobre un fenómeno central de transformación y ampliación cotidiana de la estructura del Estado Mexicano y de la conciencia nacional.

Debemos reconocer, que la Reforma del Estado en materia de comunicación, no es una reforma jurídica más para modernizar al Estado mexicano; sino que por su naturaleza vertebral que cruza todos los ámbitos de la vida comunitaria y cotidiana, es la reforma mas importante de la sociedad mexicana de principios del siglo XXI, pues es a partir de esta renovación como se determinarán las vías que modificarán o no los procesos para construir la conciencia colectiva nacional de final de milenio. De ello dependerá si se crean las bases político-sociales para generar una conciencia para el avance de la República o para su retroceso mental, social y civilizatorio en el nuevo siglo.

Para avanzar en la reforma del Estado mexicano, construir la "Nueva Política de Cultura y Comunicación Social para la Sobrevivencia Nacional” y ampliar las bases de la democracia; el nuevo gobierno federal deberá realizar, entre otras, las siguientes 14 acciones mínimas de política informativa:

1.- El Estado debe rescatar su función rectora en el campo de la comunicación frente a la dinámica salvaje que han alcanzado las fuerzas del mercado en éste terreno, para construir un nuevo proyecto de información nacional basado en la participación de las comunidades.

2.- Es necesario que se replante el pacto social de comunicación existente entre el Estado, los medios de información y la sociedad para orientarlo hacia un nuevo pacto tripartita de participación ciudadana que equilibre el actual funcionamiento desigual.

3.- Se requiere que el Poder Legislativo limite constitucionalmente las facultades discrecionales del Poder Ejecutivo en el campo de la comunicación colectiva, para crear un marco normativo más democrático y justo en el funcionamiento de los procesos de comunicación social.

4.- Es imperativo elevar a rango constitucional el acceso a la información como un bien y un derecho público al cual han de acceder y ejercer todos los mexicanos. 
5.- Es indispensable que se actualice el contexto jurídico amplio de las leyes sobre comunicación social para adaptarla a los desafíos de la sociedad nacional del siglo XXI. Para ello, es conveniente retomar el espíritu del proyecto de "Ley Federal de Comunicación Social y el Proyecto de Ley Reglamentaria de los Artículos 6 y 7 Constitucionales en Materia de Libertad de Expresión y Derecho a la Información" preparado por la Comisión de Radio Televisión y Cinematografía (RTC) de la XLVII Legislatura del Congreso para discutirlo y perfeccionarlo.

6.- Se requiere garantizar el respeto al libre ejercicio profesional del informador y facilitar su acceso a las fuentes de información públicas y privadas ${ }^{(30)}$.

7.- Se necesita garantizar el Derecho de Replica en todos los medios de comunicación como una garantía constitucional elemental ${ }^{(31)}$.

8.- Es indispensable que se discuta en el Congreso de la Unión los criterios de renovación y supervisión de las concesiones de radio y televisión para los próximos años y que no sólo dependa de la Secretaría de Comunicaciones y Transportes.

9.- Es importante que se cree la figura del Ombudsman de la comunicación, para analizar imparcialmente los conflictos de intereses que se dan en éste terreno.

10.- Es imperativo que el Estado fortalezca y amplié el esquema de medios de comunicación de servicio público para cumplir con su función de rector nacional y equilibrar el funcionamiento del modelo de comunicación de mercado.

11.- Se requiere rescatar y ampliar los pocos espacios que se han dedicado a la difusión y construcción de valores plurales y cívicos vía los medios de comunicación de masas, y proponer alternativas para impulsar la edificación de una cultura cívico-democrática más madura en nuestro país.

12.- Es necesario promover la creación de órganos plurales con participación de la sociedad civil en la vigilancia de la normatividad relacionada con el funcionamiento global de los medios de comunicación ${ }^{(32)}$.

(30) Asociación Mexicana de Derecho a la Información, Objetivos centrales, Documento Base, México, D.F. enero del 2000, páginas 5 y 6 .

(31) Ibid.

(32) Ibid 
13.- Se requiere promover el respeto irrestricto a la privacidad de los ciudadanos que impida exhibirlos ante la sociedad vía los medios de manera morbosa, injuriosa o difamante ${ }^{(33)}$.

14.- Finalmente, es necesario rescatar y preservar la memoria histórica de nuestra sociedad como parte del Derecho a la Información.

De no avanzar sobre este horizonte en el próximo gobierno, encontraremos que en plena fase de modernización nacional con los Tratados de Libre Comercio se habrán modificado las estructuras económicas, políticas, jurídicas, tecnológicas, etc. de nuestra sociedad; pero no se habrán transformado las estructuras mentales profundas que, en última instancia, son las que sostienen y le dan vida a nuestra comunidad. Bajo estas circunstancias la sociedad mexicana estará avanzando con los "ojos vendados" por un precipicio muy peligroso y dentro de algunos años veremos y sufriremos las consecuencias devastadoras que habrá dejado sobre nuestra conciencia y comportamientos colectivos la presencia del funcionamiento desregulado de la lógica de mercado en el terreno cultural y espiritual de nuestro país.

De otra forma, teniendo posibilidades de sobra para comprender hacia donde tiende a evolucionar el proyecto cerebral de nuestra sociedad ante el fenómeno de la globalización cultural y de aplicar las medidas correctivas necesarias para mantener el rumbo de comunidad autónoma; habremos elegido el camino de la incondicionalidad ideológica que nos lleva a convertirnos en "siervos" que no buscan alternativas ante el proyecto de la "modernización"; sino a someternos dócilmente a ésta: Entonces habremos entrado por propia voluntad en el "Fast Track de la desnacionalización y el extravío Mental".

(Recibido el 2-9-2000, aceptado el 16-9-2000)

(33) Ibid. 